Preprint of the article

J. Carmona, M.A. Climent, P. Garcés, Influence of different ways of chloride contamination on the efficiency of cathodic protection applied on structural reinforced concrete elements, Journal of Electroanalytical Chemistry, 793 (2017)

http://dx.doi.org/10.1016/j.jelechem.2016.08.029

If you wish a pdf of the published final version of the article:

You can obtain the pdf published version from the web page of Elsevier for free, until $10^{\text {th }}$ August 2017 at the following link:

https://authors.elsevier.com/a/1VFaS5bbJ5NkdT

After that date, please ask any of the authors for a copy of the pdf, for instance through researchgate.net 


\title{
Influence of different ways of chloride contamination on the efficiency of cathodic protection applied on structural reinforced concrete elements
}

\author{
J. Carmona*, M.A. Climent, P. Garcés \\ Civil Engineering Department, University of Alicante, PO Box 99, 03080 Alicante, Spain. \\ (*): Corresponding author. Phone: +34 649812668. E-mail address: jcarmona@ua.es
}

\begin{abstract}
Cathodic protection is a method to protect reinforced concrete structures located in saline environments against corrosion effect produced by $\mathrm{Cl}^{-}$penetration. But there are significant differences among these aggressive environments. The aim of this article is to show how different ways of saline contamination can affect the efficiency of cathodic protection. For this research, a series of laboratory specimens representing structural elements were subjected to two versions of cathodic protection (cathodic protection strictly speaking, and cathodic prevention), while two different ways of saline contamination were applied (permanent immersion in a $\mathrm{NaCl}$ solution and periodic pouring of discrete amounts of a $\mathrm{NaCl}$ solution in atmospheric exposure). Depending on the saline environment, differences in the efficiency of cathodic protection were detected. Results can be useful to determine the specific features of the cathodic protection to be applied in each case, taking into account both the initial $\mathrm{Cl}^{-}$ content of the structural element and the particular saline environment where it is located.
\end{abstract}

Keywords: cathodic protection; cathodic prevention; chloride penetration; saline environment; reinforced concrete.

\section{Introduction}

Environments characterized by a significant presence of chlorides $\left(\mathrm{Cl}^{-}\right)$are undoubtedly the most aggressive contamination danger for reinforced concrete. $\mathrm{Cl}^{-}$ions can either be present in the concrete mix or penetrate through the pore network of the concrete protecting cover of the steel rebar. When $\mathrm{Cl}^{-}$reaches the reinforcement surface and under normal conditions (presence of oxygen and water), corrosion can be triggered. Exceeding a certain $\mathrm{Cl}^{-}$concentration threshold, and from a determined electrochemical potential of the steel (mainly related to the $\mathrm{O}_{2}$ presence in its surface), its protective oxide film (passive layer) starts to be affected by pitting corrosion. The method called cathodic protection (CP) has been utilized for a long time to prevent the corrosion process or at least mitigate its effects. It is a 
system generally used to protect metals against the corrosion process. This procedure can be applied in two ways: by sacrificial anodes or by impressed current, although hybrid treatments have been also carried out [1]. CP principle consists in reducing the electrochemical potential of the metal to be protected [2]. This action allows to lessen both the corrosion rate and the activity of the electrochemical corrosion cells. In the case of reinforced concrete exposed to a $\mathrm{Cl}^{-}$environment, some valuable side effects are the barrier effect against $\mathrm{Cl}^{-}$penetration, the $\mathrm{Cl}^{-}$and $\mathrm{O}_{2}$ removal together with the generation of $\mathrm{OH}^{-}$ions. The conjunction of these consequences helps to inhibit the corrosion process despite a serious $\mathrm{Cl}^{-}$contamination. A clear and rigorous explanation about it was exposed in previous research [3]. From the seventies of the past century, $\mathrm{CP}$ has been adapted for the protection of reinforced concrete steel rebar. R.F. Stratful was probably the first one in applying $\mathrm{CP}$ to bridge decks $\mathrm{Cl}^{-}$ contaminated by de-icing salts [4] and ever since, a broad investigation on this matter has been developed [5-7]. Regarding the impressed current version of CP, the anode system is perhaps the most complex element and therefore the subject of further investigations. Currently, a wide range of anode materials are being used: from oxide activated high conductive metals to a new generation of modified cementitious materials, generally with carbon-related products and composites [8-13]. Also, assemblies composed by metal-carbon cementitious material mixes are recently proposed as anodes for CP [14-16]. For the present research, the anode system was basically composed of a thin layer of graphite-cement paste (GC), as was carried out initially for electrochemical chloride extraction [17-19], and recently adapted to cathodic protection. [20].

Generally, two kinds of cathodic protection methods are known: cathodic protection strictly speaking (CP) and cathodic prevention (CPre), as was for the first time stated by Pedeferri et al. [21, 22]. CP is usually applied to structures that have developed corrosion. CP impressed current density is usually in the range $8-20 \mathrm{~mA} / \mathrm{m}^{2}$. CPre is defined as a particular case of $\mathrm{CP}$, able to maintain the steel of new reinforced concrete structures in passivation (maintenance of the passive layer protective effects), despite the increase of chloride content on the rebar surface due to $\mathrm{Cl}^{-}$contaminations during their service life. CPre is commonly applied with 1-2 mA/m² of current density.

The $\mathrm{Cl}^{-}$contamination pathways of reinforced concrete structures may be classified into two major groups, namely:

-Location in aggressive saline environments (which the most common is the marine environment)

- Operating contamination, such as the use of de-icing salt in wintertime on road structures (bridges, parking buildings, etc.)

This work aims to determine how different routes of $\mathrm{Cl}^{-}$contamination influence the efficiency of both types of cathodic protection. This efficiency was assessed analyzing the 
ability of CP treatments to keep or recover protective conditions of the steel reinforcement (100 mV and $150 \mathrm{mV}$ decay criterion). Besides, it was determined the reduction of $\mathrm{Cl}^{-}$ penetration caused by the treatments, the so-called "barrier effect" [20, 21].

Both electrochemical treatments (CP and CPre) were applied to laboratory specimens, subjected at the same time to two different forms of $\mathrm{Cl}^{-}$contamination:

-Contamination A: ponding of a $1 \mathrm{M} \mathrm{NaCl}$ solution onto the concrete surface coated by the GC anode.

-Contamination B: spraying $65 \mathrm{ml}$ of $0.5 \mathrm{M} \mathrm{NaCl}$ solution once a week on the same location

Prismatic shaped specimens to be treated with $\mathrm{CP}$ were manufactured with salt in the mixing water. In this way, the presence of a significant amount of $\mathrm{Cl}^{-}$close to the rebar ( $2 \%$ of $\mathrm{Cl}^{-}$relative to cement mass) was assured right from the beginning of the study. The aim was to check the capability of CP to keep and restore the steel protection conditions with such high chloride contents along the electrochemical treatment and the contamination process.

The other specimens to be subjected to CPre were free of salt, as in newly built and therefore not yet $\mathrm{Cl}^{-}$contaminated structures.

The means to know how different kinds of $\mathrm{Cl}^{-}$contamination affect the efficiency level of $\mathrm{CP}$ and $\mathrm{CPre}$ treatments were the study of the following aspects:

-Time during which the passivation (protective conditions) of reinforced concrete rebar was preserved by the $\mathrm{CP}$ electrochemical treatments in both kinds of contamination.

-Assessment of the $\mathrm{CP}$ and CPre barrier effect, based on the evolution of $\mathrm{Cl}^{-}$content profiles in the mass of concrete samples during the processes.

-Ability of the $\mathrm{CP}$ to restore steel protective conditions after they were lost because of the suffered contamination.

The three considered aspects were always evaluated by comparing the specimens subjected to electrochemical treatment with their reference specimens, which had the same composition and were equally contaminated, but without any electrochemical treatment.

\section{Materials and methods}

\subsection{Laboratory specimens}

Laboratory specimens were designed as concrete prisms with dimensions $18 \times 18 \times 8$ $\mathrm{cm}^{3}$, with reinforcements of six steel bars $5 \mathrm{~mm}$ diameter soldered symmetrically forming squares of $5 \mathrm{~cm}$ side, and placed $2 \mathrm{~cm}$ under the closest external surface, where the anodic system will be placed. Rebar was connected to the negative pole of the electric source, using plastic isolated copper connectors (see Figure 1). 

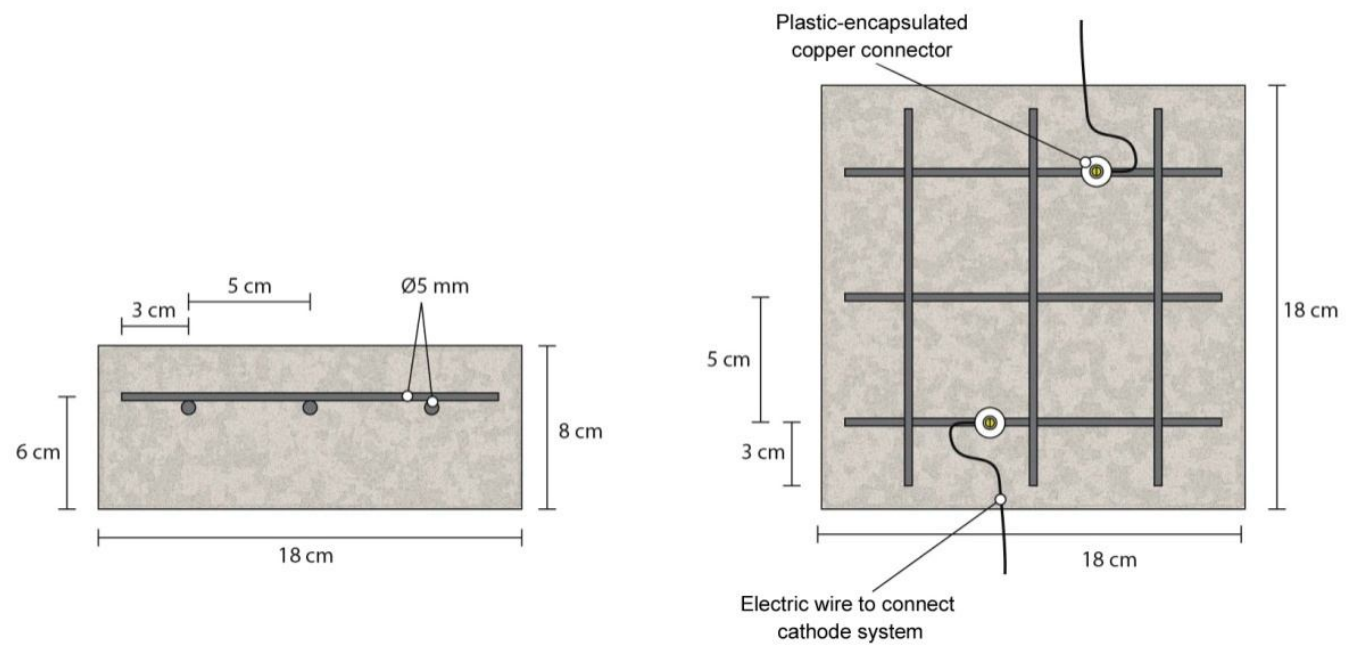

Figure 1. Laboratory specimens. Dimensions and reinforcement. Adapted from [20].

The approach taken to prepare the laboratory specimens as reinforced slabs was to obtain a concrete with a minimum risk of shrinkage cracks, and a good workability due to the complex formwork. But at the same time, with the characteristics of a conventional concrete. Thus, we manufactured the samples with a low content of cement $\left(250 \mathrm{~kg} / \mathrm{m}^{3}\right)$, a high water/cement ratio $(0.65)$ but with the addition of a superplastizicer. This special flowability assured a good compactness using a vibrating table and a high energy of compaction.

Concrete specimens were manufactured with a dosage as follows (Table 1).

\begin{tabular}{ccc}
\hline $\begin{array}{c}\text { MATERIALS IN } \\
\text { CONCRETE }\end{array}$ & $\begin{array}{c}\text { Samples for CP } \\
\left(\mathbf{k g} / \mathbf{m}^{\mathbf{3}}\right)\end{array}$ & $\begin{array}{c}\text { Samples for CPre } \\
\left(\mathbf{k g} / \mathbf{m}^{\mathbf{3}}\right)\end{array}$ \\
\hline $\begin{array}{c}\text { Portland cement CEM I 42.5 R } \\
\text { Limestone aggregates } 12 \mathrm{~mm}\end{array}$ & 250 & Same \\
maximum size & 1,890 & Same \\
Water/cement ratio & 0.65 & Same \\
Superplasticizer & 2.50 & Same \\
NaCl in mixing water & $2 \% \mathrm{Cl}^{-}$relative to & Nil \\
& cement mass & \\
\hline
\end{tabular}

Table 1. Concrete dosage for laboratory specimens

Concrete samples manufactured in this way were moist-cured by means of a curing chamber at $>95 \%$ relative humidity (RH) for 28 days. Under these conditions, concrete got standard quality properties: compressive strength $37.8 \mathrm{~N} / \mathrm{mm}^{2}$, porosity $11.1 \%$ and bulk 
density $2,380 \mathrm{~kg} / \mathrm{m}^{3}$. Therefore, laboratory specimens manufactured in this way can rightly represent a structural element of conventional reinforced concrete.

To set up the anode system, a graphite-cement paste (GC) was prepared by mixing graphite powder and Portland cement at 50\%-50\% in mass, with a water to solid mix ratio of 0.8. On that subject, the criteria stated in previous researches based on this kind of anodic system [17-20] was followed. A layer $2 \mathrm{~mm}$ thick of this paste was applied on the top face of each specimen, and after that all of them were placed in the curing chamber for 10 days.

Test configuration and connections with the electric source were made up as shown in Figure 2.
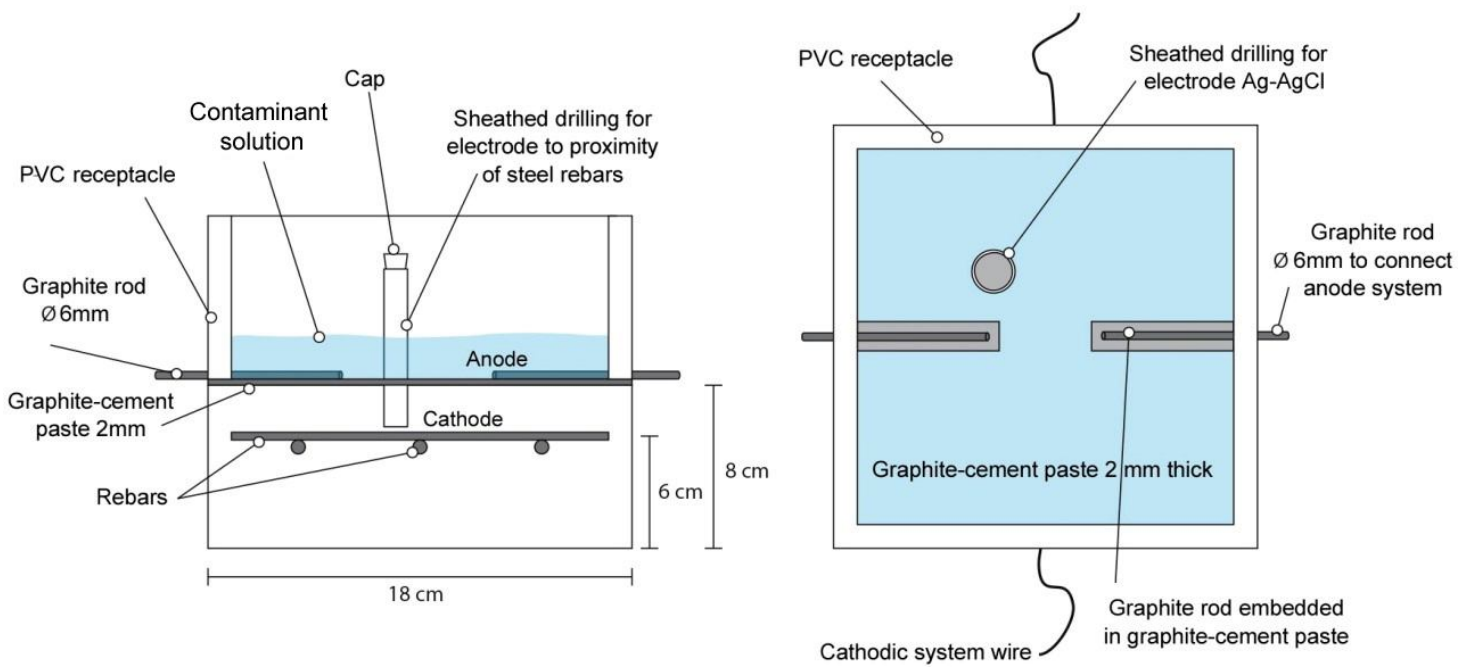

Figure 2. Laboratory specimens. Design and manufacturing scheme. Adapted from [20].

To connect to the positive pole of the electric source, two graphite rods were embedded in the GC layer as primary anodes, avoiding any contact between graphite rods and concrete. Rod ends protruded from the sample in order to attach the copper wires. A PVC receptacle was assembled with adhesive on the top of the samples to retain the contaminant solution.

Besides to ensure one kind of contamination, the fact to dam the contamination solutions over the anode was also the way to check the durability of the GC layer from which it was made.

The ratio between the surface of concrete covered by the anodic GC layer and the surface of the primary anodes (graphite rods) was 9.6, and the ratio between the same GC layer relative to the total surface of the steel bars was 1.7.

The resistivity of the GC was measured through the four-probe method. For this purpose, paste specimens were cast in $4 \times 4 \times 16 \mathrm{~cm}^{3}$ molds, and moist-cured for 14 days in the same above mentioned curing chamber. The experimental details of the measurements can be found elsewhere [23]. The average value of resistivity obtained was $1.5 \Omega \mathrm{m}$. 
In order to monitor the steel corrosion potential $\left(\boldsymbol{E}_{\text {corr }}\right)$ and the different electrode potentials, an $\mathrm{Ag}-\mathrm{AgCl}$ reference electrode was placed in each sample. It was kept in a housing hole drilled from the anode surface to the rebar proximity (see Figure 2). The housing was sheathed with a plastic tube, and filled with a $\mathrm{KOH} 0.2 \mathrm{M}$ solution.

Ten specimens were manufactured in this way: Five of them with salt in the mixing water (named "the saline series") to perform the CP tests, and the other five without salt (named "the non-saline series") for the study of CPre process. Both treatments were carried out in two different contamination ways, as follows:

-Contamination A (A). The anodic exposed surface (that is overlaid by GC layer) was kept immersed in a $1 \mathrm{M} \mathrm{NaCl}$ solution. From now on, samples contaminated in way A will be called "A contaminated".

- Contamination B (B). It consisted in spraying $65 \mathrm{ml}$ of $0.5 \mathrm{M} \mathrm{NaCl}$ solution once a week. It tried to represent a lighter contamination. From now on, samples contaminated in way B will be called "B contaminated"

\subsection{Cathodic protection $(C P)$ method. $1^{\text {st }}$ phase.}

For the first phase of 24 weeks, CP treatment was applied with a constant current density of $15 \mathrm{~mA} / \mathrm{m}^{2}$ relative to exposed concrete or anode surface $\left(25.5 \mathrm{~mA} / \mathrm{m}^{2}\right.$ relative to the steel bars surface), to two specimens of the "saline series". The recommendation for the CP current density is in the range $5-20 \mathrm{~mA} / \mathrm{m}^{2}$ to the steel reinforcement [28]. Other relevant works reported the recommendation of using $10-15 \mathrm{~mA} / \mathrm{m}^{2}$ referred to the concrete surface overlaid by an anode of cementitious mortar embedding conductive fibers [29]. In the present study, the pathways of contamination are especially severe. This was the reason to choose for $\mathrm{CP}$ an impressed current with a density in the high side of the conventional range. Previous researches of the same authors of this paper confirmed a good behavior of $\mathrm{CP}$ in the range $15-40 \mathrm{~mA} / \mathrm{m}^{2}$ [20]. No damages were detected in the GC anode after a similar period of CP application.

Meanwhile, each of them was subjected to each of both different ways of contamination, $\mathrm{A}$ and $\mathrm{B}$. Their denominations were ACP and BCP, respectively. In order to evaluate the contamination process without the $\mathrm{CP}$ effect, other two samples of the same series were subjected to the same contamination regimes during the same period of 24 weeks, but without any electrochemical treatment. They are the reference samples, named ACPRef and BCPRef. These samples had also a GC layer on the top side, in order to assure a proper comparison with the electrochemically treated specimens. The last fifth sample served as starting point of reference, only to know the initial $\mathrm{Cl}^{-}$profile as a result of the addition of salt in the mixing water. Obviously, this sample did not have the GC layer on top. Along those 24 weeks, CP was continuously applied during the first 13 . At that time, the impressed current was switched 
off for 4 weeks, and then CP was reconnected until the end of this 24-week phase. Contamination processes were applied continuously during the 24 weeks, without interruption. Nomenclature of that samples are summarized in Table 2.

\subsection{Cathodic prevention (CPre) method}

CPre was implemented with the same schedule that $\mathrm{CP}$, simultaneously and under the same conditions as $\mathrm{CP}$, to properly compare the results of both treatments. In this case, current density was $2 \mathrm{~mA} / \mathrm{m}^{2}$ relative to exposed concrete or anode surface $\left(3.4 \mathrm{~mA} / \mathrm{m}^{2}\right.$ relative to the steel bars surface). Test samples were the five ones of the "non-saline series". All of them were treated in the same way that for CP method (application of both ways of $\mathrm{Cl}^{-}$ contamination). The ones treated with CPre were designed as ACPre and BCPre, and the other ones also subjected to $\mathrm{Cl}^{-}$contamination but non CPre treated were ACPreRef and BCPreRef. Despite the samples for CPre were manufactured without salt, the possible small content of $\mathrm{Cl}^{-}$coming from its presence in tap water or in the aggregates was detected by the $\mathrm{Cl}^{-}$profile of the fifth sample of this series. Nomenclature of samples for CPre is also shown in Table 2.

\begin{tabular}{ccccc}
$\begin{array}{c}\text { Techniques and } \\
\text { reference } \\
\text { samples }\end{array}$ & CP & $\begin{array}{c}\text { Reference } \\
\text { samples for } \\
\text { CP }\end{array}$ & CPre & $\begin{array}{c}\text { Reference } \\
\text { samples for } \\
\text { CPre }\end{array}$ \\
\hline A contamination & ACP & ACPRef & ACPre & ACPreRef \\
B contamination & BCP & BCPRef & BCPre & BCPreRef \\
\hline
\end{tabular}

Table 2. Nomenclature of specimens

\subsection{Cathodic protection $(C P)$ method. $2^{\text {nd }}$ phase.}

Monitoring verified that all the specimens had lost their protection conditions at the end of week 17, 4 weeks after the suspension of electrochemical treatments at week 13. Besides, 
with the same current density $\left(15 \mathrm{~mA} / \mathrm{m}^{2}\right)$ along the following 4 weeks, $\mathrm{CP}$ had shown to be unable to recover the steel passivation conditions. The same result was obtained for samples subjected to CPre with $2 \mathrm{~mA} / \mathrm{m}^{2}$ of current density. $\boldsymbol{E}_{\text {corr }}, \boldsymbol{i}_{\text {corr }}$ and $\Delta \boldsymbol{E}_{\text {decay }}$ values of all specimens were very clear at this point. Therefore, a second phase of CP treatment was implemented to all specimens, progressively increasing $\mathrm{CP}$ current density in order to achieve the return to protection conditions of the reinforcements. Each new CP current density was applied during 4 weeks. If the objective was not reached at the end of this period, a higher value of current density was attempted. This second phase started with $20 \mathrm{~mA} / \mathrm{m}^{2}$, and ended with $40 \mathrm{~mA} / \mathrm{m}^{2}$.

\subsection{Determination of $\mathrm{Cl}^{-}$content profiles}

Right after the end of $1^{\text {st }}$ phase, a drilled concrete core was extracted from each specimen in order to find out the $\mathrm{Cl}^{-}$content at different depths. The grinding method was based on RILEM TC 178-TMC recommendations [24]. Thus, considering that the specimens concrete cover was $20 \mathrm{~mm}, 10$ dust samples were extracted each $2 \mathrm{~mm}$ depth, from the external concrete surface to the rebar. The measurement of the acid-soluble $\mathrm{Cl}^{-}$contents of samples was carried out by potentiometric titration following the procedures stated by previous researches $[25,26]$. Values were always expressed as percentage relative to mass of cement in concrete. In this way, it was possible to obtain the $\mathrm{Cl}^{-}$content profile of each specimen, in order to assess the evolution of $\mathrm{Cl}^{-}$presence in the concrete mass along the referred processes of $\mathrm{CP}$ and $\mathrm{CPre}$ and both types of contamination (A and $\mathrm{B}$ ).

\subsection{Monitoring}

Along the 24 weeks of the phase 1, monitoring consisted in the following measurements:

-Steel corrosion potential ( $\left.\boldsymbol{E}_{\text {corr }}\right)$. This parameter was weekly measured with no electrical power, using the above mentioned $\mathrm{Ag}-\mathrm{AgCl}$ reference electrode, in $\mathrm{mV}(\mathrm{Ag}-\mathrm{AgCl})$.

-Steel corrosion rate $\left(\boldsymbol{i}_{\text {corr }}\right)$. Also weekly and with no electrical power, this value in $\mu \mathrm{A} / \mathrm{cm}^{2}$ was obtained with a Gecor6 device (Geocisa, Madrid, Spain). Gecor6 is a portable monitoring unit founded on the linear polarization resistance method. The equipment uses a modulation confinement technique, allowing the quantitative determination of the corrosion rate [27].

The procedure to monitoring $\boldsymbol{E}_{\text {corr }}$ and $\boldsymbol{i}_{\text {corr }}$ was as follows: the same day at the same hour of each week, current of all treatments was switched off, and remained in that manner during 24 hours. At this moment, $\boldsymbol{E}_{\text {corr }}$ and $\boldsymbol{i}_{\text {corr }}$ were measured. The purpose of waiting 24 hours without current to check those parameters was to avoid the influence of the polarization in the measurements. 
-Feeding voltage $\left(\Delta \boldsymbol{E}_{\text {feed }}\right)$, which represents the electromotive force necessary to maintain constant the chosen current density along the treatments. Each week the feeding voltage of each specimen, $\Delta \boldsymbol{E}_{\text {feed }}$ in $\mathrm{mV}$, was determined as the potential difference between cathode and anode.

The checking of $\Delta$ Efeed is useful in order to consider possible damages in the GC anode or in the concrete in contact with it. Homogeneous and almost continuous $\Delta$ Efeed values indicate good condition of the anode system, while sharp increases of that parameter show damages in the anode [20,29].

-Individual potentials of the anode and the cathode $\left(\boldsymbol{E}_{\mathrm{a}}\right.$ and $\boldsymbol{E}_{\mathrm{c}}$, respectively), were measured in $\mathrm{mV}$ between each electric pole and the reference electrode $\mathrm{Ag}-\mathrm{AgCl}$.

It is a way to assure a good performance of the impressed current, because $\mathrm{Ea}+\mathrm{Ec}$ must be equal to Efeed in absolute values.

-Depolarization $\left(\Delta \boldsymbol{E}_{\text {decay }}\right)$. To control the efficiency of CP and CPre as keepers of protection conditions of steel, the "100 $\mathrm{mV}$ decay" criterion was used, as is specified in ISO 12696:2012 [28]. This criterion has been also extensively employed for this purpose by several researchers $[29,30]$. The method consists in obtaining the 4 hours potential decay ( $\Delta \boldsymbol{E}_{\text {decay }}$ ), as the difference between $\boldsymbol{E}_{\mathrm{c}}$ (h) (the value of $\boldsymbol{E}_{\mathrm{c}} 4$ hours after the current switch off), and the instant-off cathodic potential $\boldsymbol{E}_{\mathrm{c}}^{\text {io }}$, (the value of this parameter measured $1 \mathrm{~s}$ after the current switch off). It is understood that $\Delta \boldsymbol{E}_{\text {decay }}$ values above $100 \mathrm{mV}$ implies an adequate corrosion protection of steel (passivation conditions) [28]. Values of $\boldsymbol{E}_{\mathrm{c}}$ io were monitored by means of an automatic data logger able to obtain and record 500 measurements along the 6 seconds after the current switch off.

Besides the rule of $100 \mathrm{mV}$ of depolarization, ISO 12696:2012 [28] stated other checking to assure the protection conditions of steel. This is the $150 \mathrm{mV}$ of depolarization after more than 24 hours of the current stop. For this research, these values were taken as the difference between the instant-off cathodic potential and the same parameter measured 7 days after the current switch off, and checked along 4 weeks. Only one of this two conditions is required to consider the steel in protection conditions. Intending to strengthen certainty on the state of steel in protection conditions, both conditions were monitored, and the second one during 4 weeks, in order to test its stability.

\section{Results and discussion}

\subsection{CP treatment $1^{\text {st }}$ phase}

Fig. 3 shows the evolution of $\boldsymbol{E}_{\text {corr }}$ values for the specimens along the first phase of CP (24 weeks). Both samples, ACP and BCP only kept values above $-300 \mathrm{mV}$ for 4 weeks. CP with $15 \mathrm{~mA} / \mathrm{m}^{2}$ was unable to keep protection conditions for both kinds of contamination. 


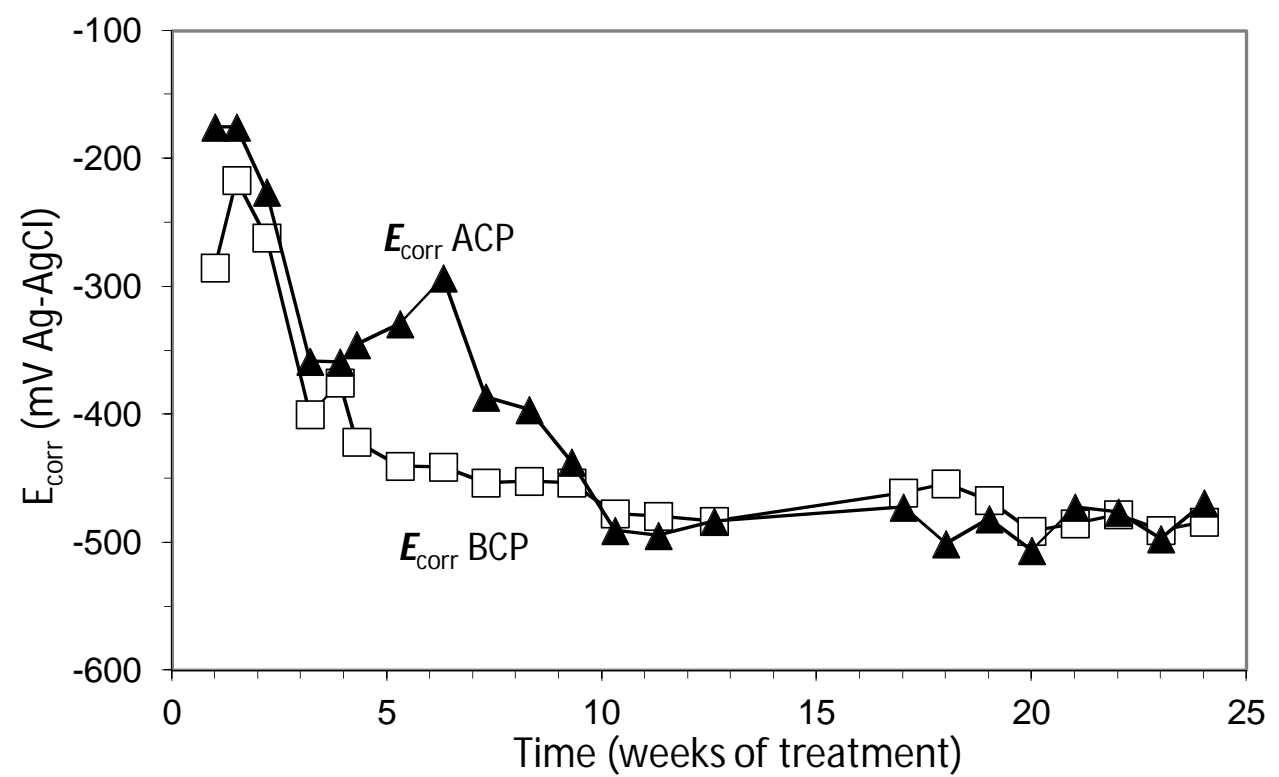

Figure 3. Evolution of $\boldsymbol{E}_{\text {corr }}$ for ACP and BCP during the $1^{\text {st }}$ phase of CP treatments (24 weeks). ACP is the A contaminated sample, BCP is the B contaminated sample. Current density: $15 \mathrm{~mA} / \mathrm{m}^{2}$, relative to exposed concrete surface. Current switched off between weeks 13 to 17. Adapted from [20].

Average measurements of $\boldsymbol{i}_{\text {corr }}$ appeared to confirm this trend, because both samples presented values above $1 \mu \mathrm{A} / \mathrm{cm}^{2}$ since week 4 . Values lower than 0.5 registered for ACP during weeks 7 to 10 were not considered as significant (see Fig. 4).

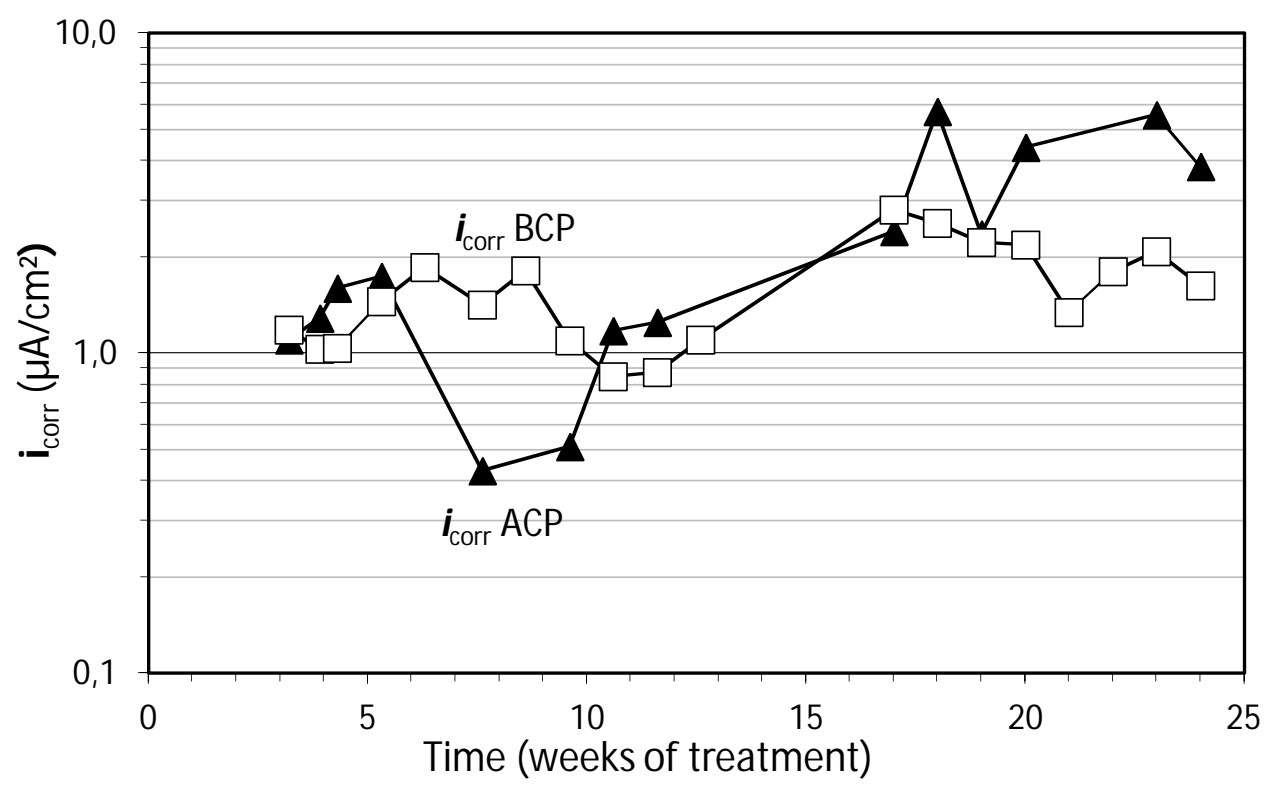

Figure 4. Evolution of $\boldsymbol{i}_{\text {corr }}$ for ACP and BCP during the $1^{\text {st }}$ phase of $\mathrm{CP}$ treatments (24 weeks). ACP is the A contaminated sample, BCP is the B contaminated sample. Current 
density: $15 \mathrm{~mA} / \mathrm{m}^{2}$, relative to exposed concrete surface. Current switched off between weeks 13 to 17 . Adapted from [20].

Next, the same parameters are shown for reference samples, also contaminated in both ways (A and B) but without electrochemical treatments. To compare with samples subjected to $\mathrm{CP}$, these ones were also manufactured with salt to obtain $2 \% \mathrm{of} \mathrm{Cl}^{-}$relative to cement mass, and the same GC anode was implemented on their surface. ACPRef was the A contaminated sample and BCPRef was the B contaminated sample. See Figs. 5 and 6.

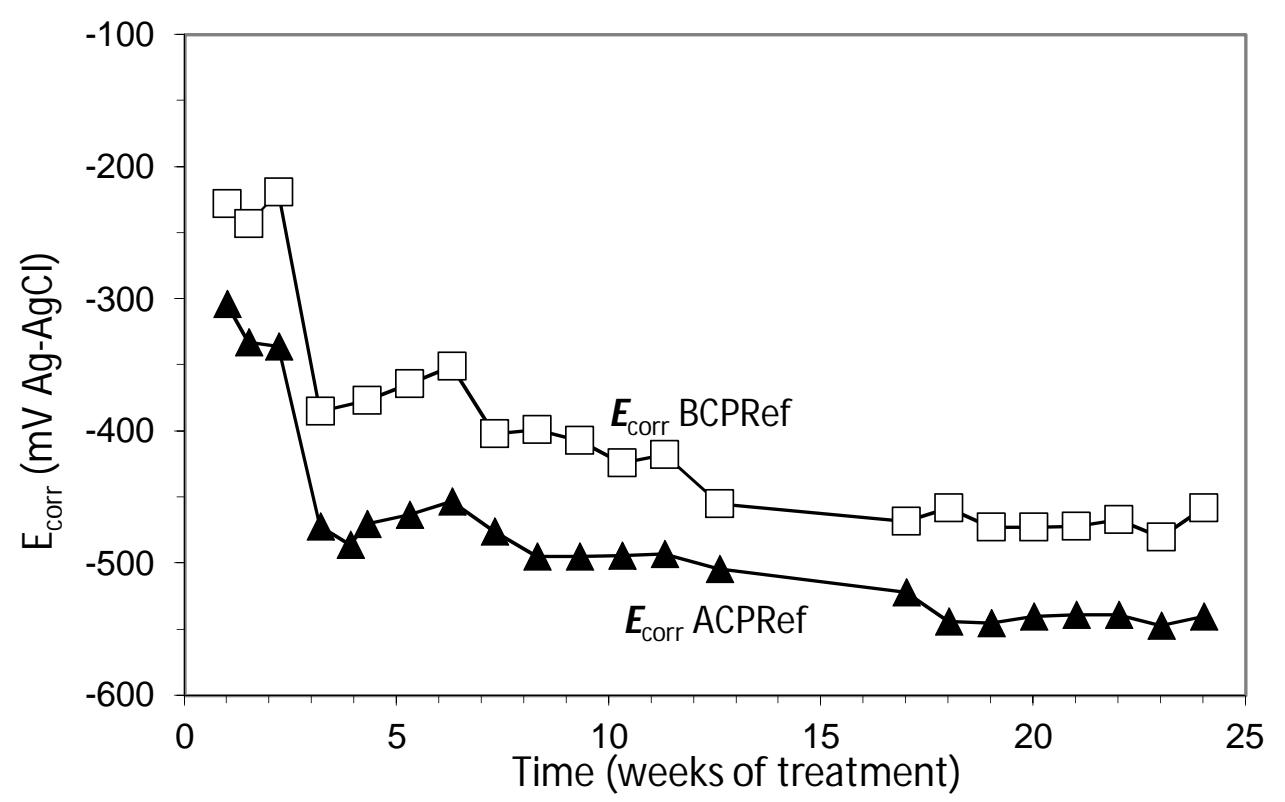

Figure 5. Evolution of $\boldsymbol{E}_{\text {corr }}$ for ACPRef and BCPRef during the $1^{\text {st }}$ phase of the testing program (24 weeks). ACPRef is the A contaminated sample, BCPRef is the B contaminated sample. 


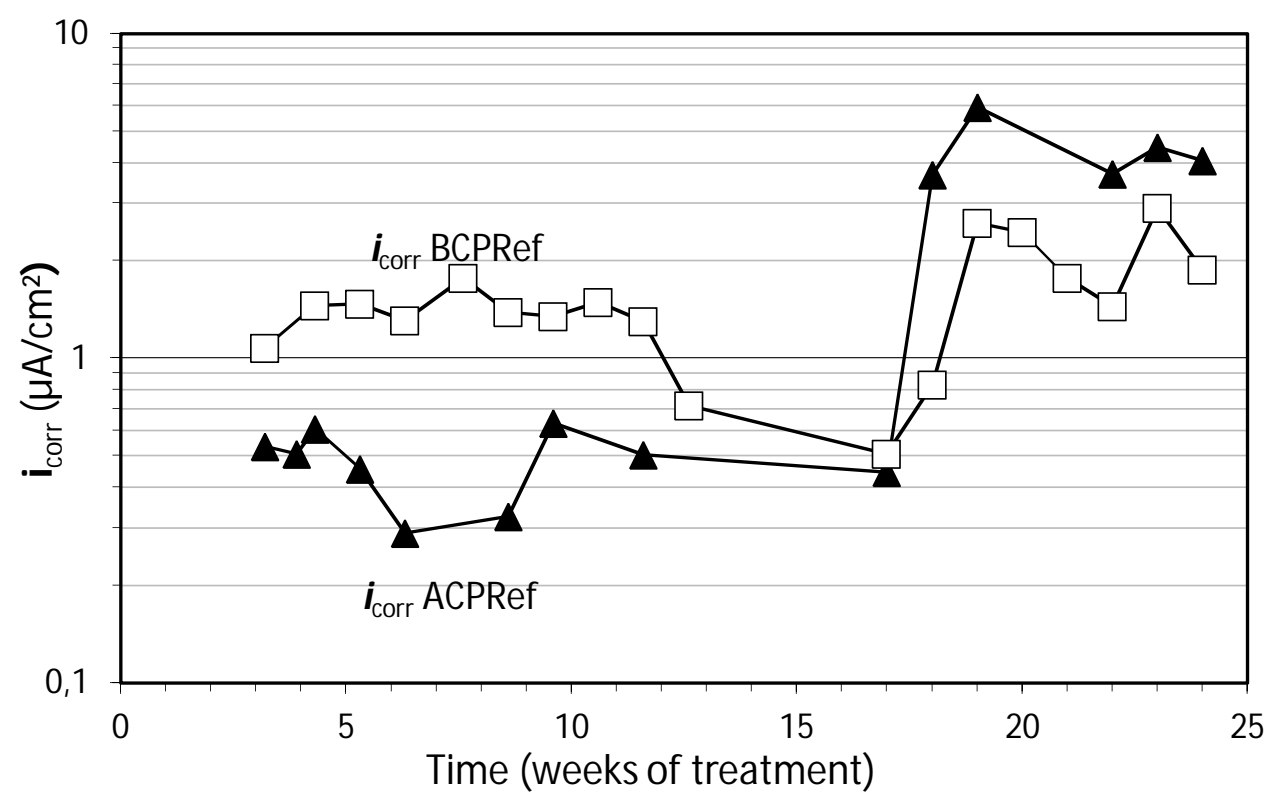

Figure 6. Evolution of $\boldsymbol{i}_{\text {corr }}$ for ACPRef and BCPRef during the $1^{\text {st }}$ phase of the testing program (24 weeks). ACPRef is the A contaminated sample, BCPRef is the B contaminated sample.

Here, $\boldsymbol{E}_{\text {corr }}$ values clearly have shown, unlike in the previous case, a more marked corrosion in A contaminated samples along the 24 weeks of the first phase. The case of $\boldsymbol{i}_{\text {corr }}$ data was not so clear, because recorded values in ACPRef remained below the BCPRef ones till $18^{\text {th }}$ week. Since then, the trend reversed.

Reviewing the feeding voltage of each specimen $\left(\Delta \boldsymbol{E}_{\text {feed }}\right)$, distinctly appeared that ACP presented smaller voltages and thus, smaller electric resistance than BCP. It may be a consequence of the higher level of saturation in ACP, due to the fact that "A contamination" consisted in ponding the $\mathrm{Cl}^{-}$solution on top of the $\mathrm{GC}$ anode. The increase of this trend since week 12 might have been caused, in addition, by the superior amount of ions (mainly $\mathrm{Cl}^{-}$) in $\mathrm{ACP}$ than in $\mathrm{BCP}$ as a consequence of the increase of $\mathrm{Cl}^{-}$penetration due to the suspension of $\mathrm{CP}$ process. This conclusion will be confirmed by obtaining the evolution of the chloride profiles in samples. See Fig. 7. 


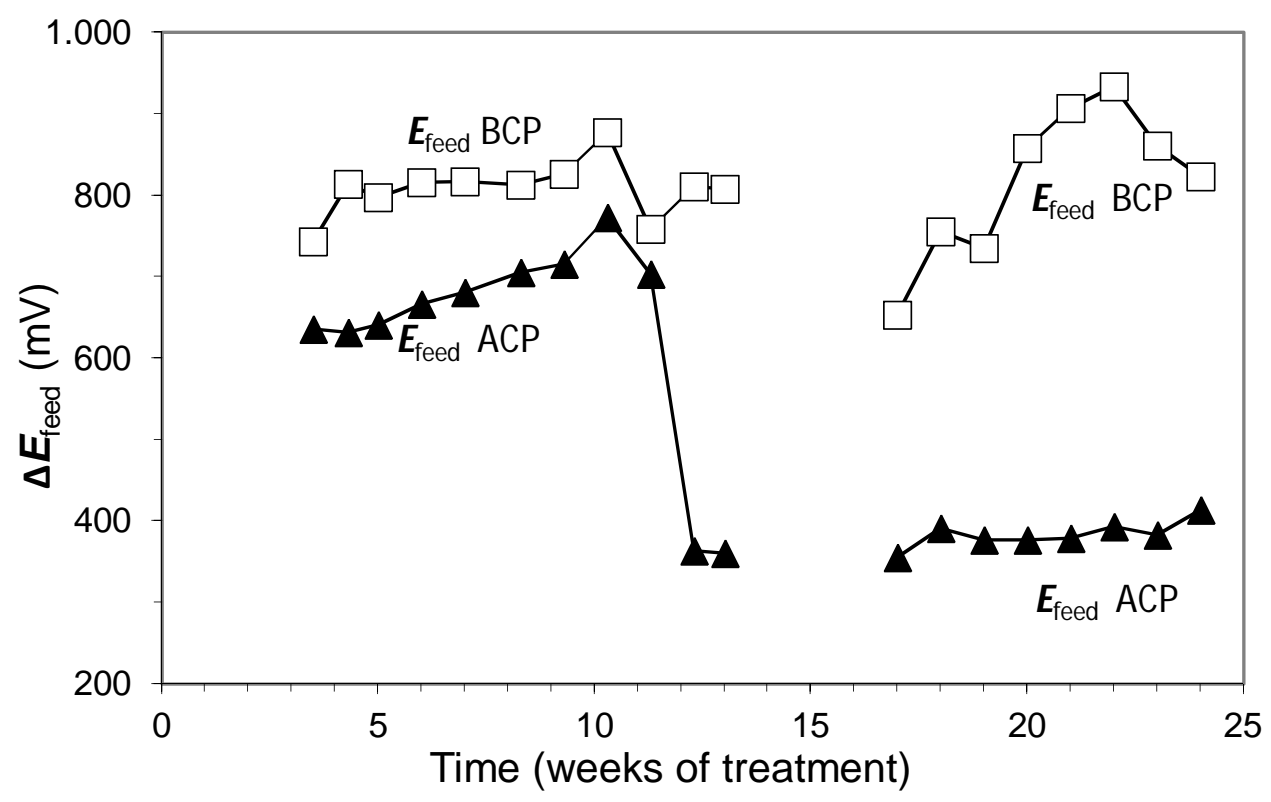

Figure 7. Evolution of $\Delta \boldsymbol{E}_{\text {feed }}$ for $\mathrm{ACP}$ and $\mathrm{BCP}$ during the $\mathrm{CP}$ treatment. $\mathrm{ACP}$ is the $\mathrm{A}$ contaminated sample, BCP is the B contaminated sample. Current density: $15 \mathrm{~mA} / \mathrm{m}^{2}$, relative to exposed concrete surface. Current was interrupted between weeks 13 to 17. Adapted from [20].

When $\Delta \boldsymbol{E}_{\text {decay }}$ is considered, it can be concluded that both routes of contamination (A and B) had similar effects. ACP values were only slightly better than those of BCP, but both shown CP unable to maintain passivation conditions beyond 4 weeks. See Figure 8.

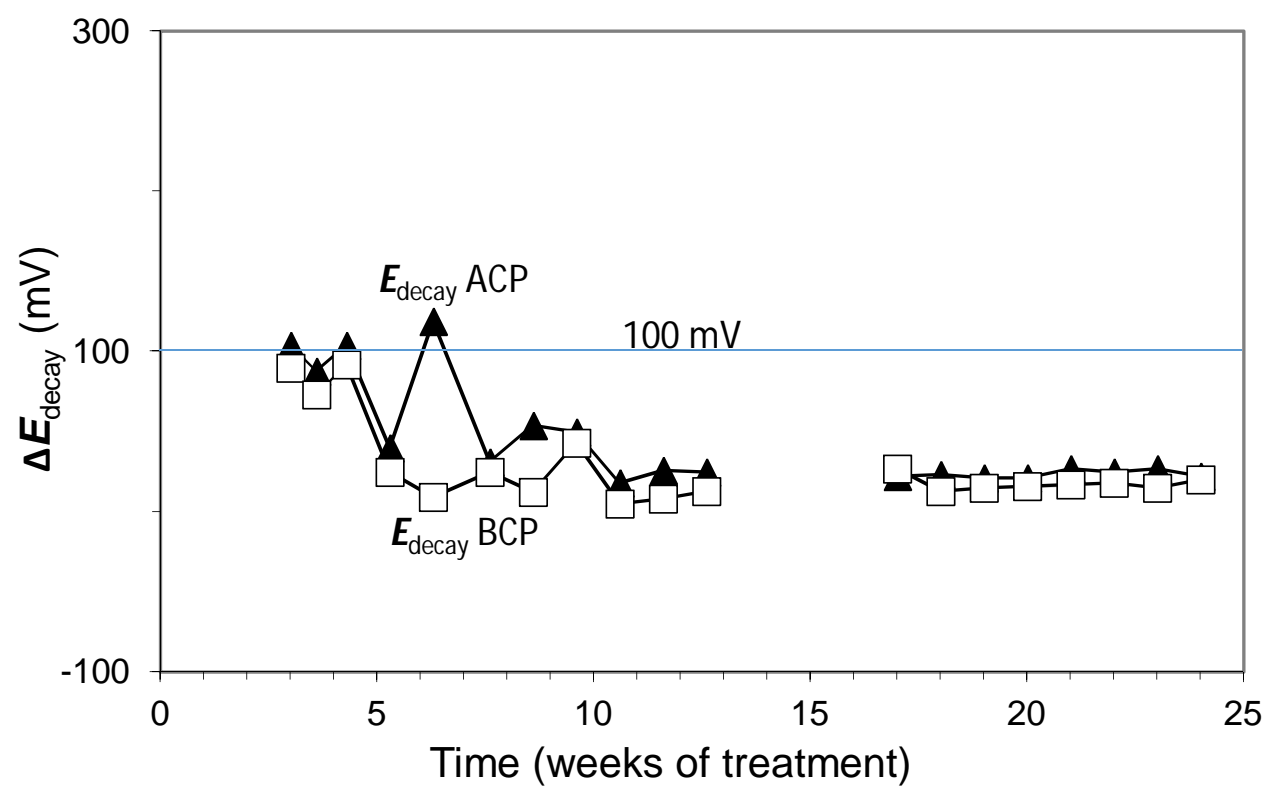

Figure 8. Evolution of $\Delta \boldsymbol{E}_{\text {decay }}$ for $\mathrm{ACP}$ and $\mathrm{BCP}$ during the $\mathrm{CP}$ treatment. ACP is the A contaminated sample, $\mathrm{BCP}$ is the $\mathrm{B}$ contaminated sample. Current density: $15 \mathrm{~mA} / \mathrm{m}^{2}$, relative to exposed concrete surface. Current was interrupted between week 13 and week 17. Adapted from [20]. 
Finally, at the end of this $1^{\text {st }}$ phase of 24 weeks, $\mathrm{Cl}^{-}$content of samples was obtained to compose $\mathrm{Cl}^{-}$profiles.

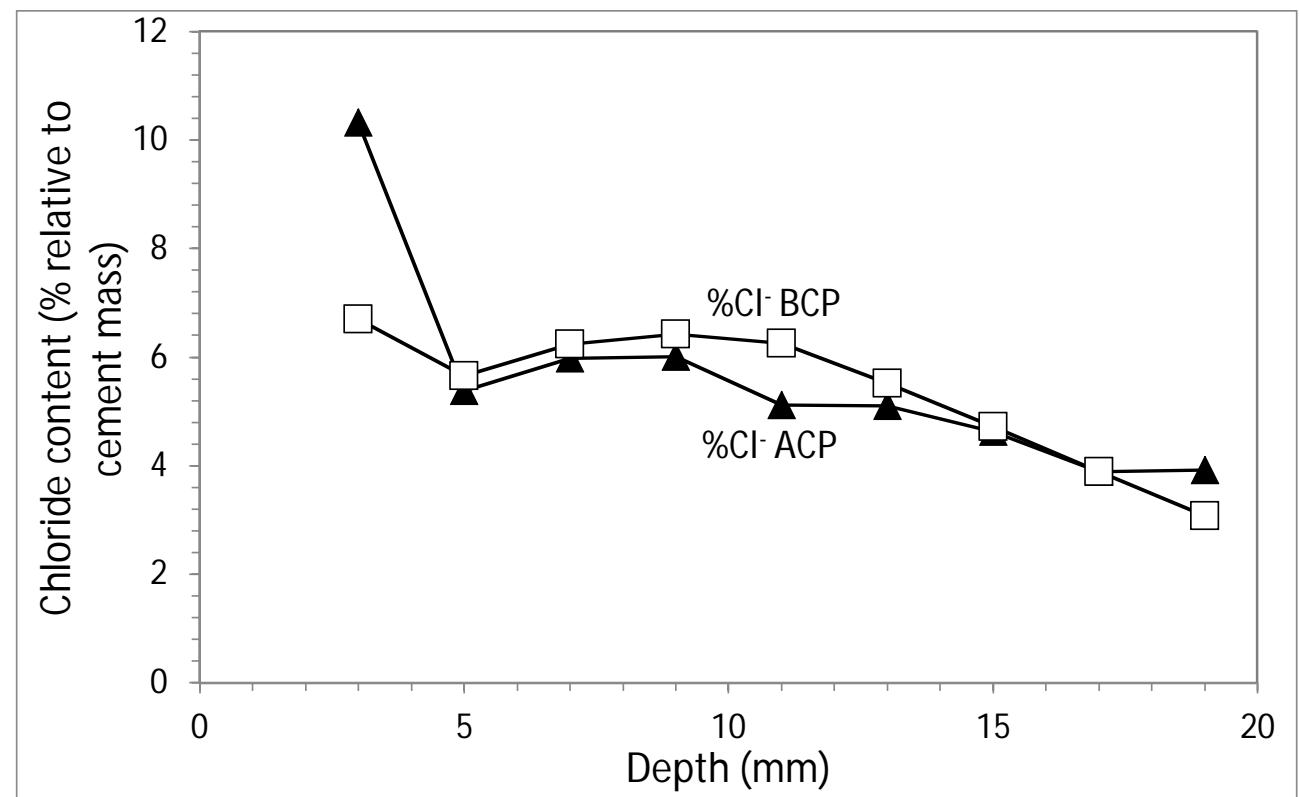

Figure 9. Profiles of $\mathrm{Cl}^{-}$content in samples subjected to $\mathrm{CP}, \mathrm{ACP}$ and $\mathrm{BCP}$ at the end of the $1^{\text {st }}$ phase of 24 weeks. Adapted from [20].

In samples subjected to $\mathrm{CP}$, results are very similar for both routes of contamination. See Figure 9.

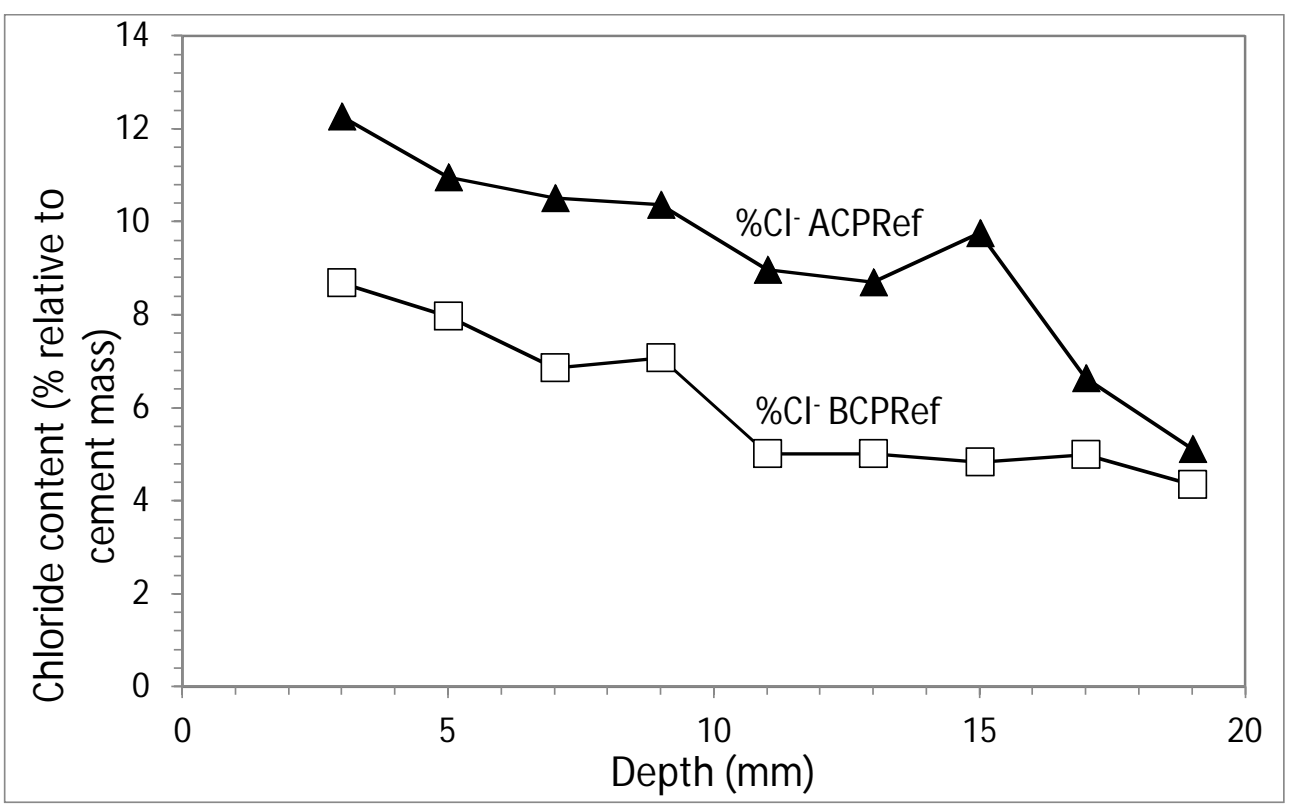

Figure 10. Profiles of $\mathrm{Cl}^{-}$content in reference samples for CP, ACPRef and BCPRef at the end of the $1^{\text {st }}$ phase of 24 weeks. Adapted from [20]. 
On the contrary, the reference samples of the "saline series" (manufactured with $2 \% \mathrm{Cl}^{-}$ relative to cement mass), contaminated in both ways (A and B) but without $\mathrm{CP}$ treatment, clearly presented A as more contaminant than B. See Figure 10.

\begin{tabular}{|c|c|c|c|c|c|c|c|c|c|}
\hline $\begin{array}{l}\text { Depth } \\
(\mathrm{mm})\end{array}$ & $\begin{array}{c}\text { Initial } \mathrm{Cl}^{-} \\
\text {contents } \\
\text { of "saline } \\
\text { series" } \\
\text { samples } \\
\left(\% \mathrm{Cl}^{\prime}\right)\end{array}$ & $\begin{array}{c}\mathrm{ACP} \\
\left(\% \mathrm{Cl}^{-}\right)\end{array}$ & $\begin{array}{c}\text { Increase } \\
\text { of } \mathrm{Cl}^{-} \text {in } \\
\mathrm{ACP} \\
\left(\% \mathrm{Cl}^{-}\right)\end{array}$ & $\begin{array}{c}\text { ВCP } \\
\left(\% \mathrm{Cl}^{-}\right)\end{array}$ & $\begin{array}{c}\text { Increase } \\
\text { of } \mathrm{Cl}^{-} \text {in } \\
\mathrm{BCP} \\
\left(\% \mathrm{Cl}^{-}\right)\end{array}$ & $\begin{array}{c}\text { ACPRef } \\
\left(\% \mathrm{Cl}^{-}\right)\end{array}$ & $\begin{array}{l}\text { Increase } \\
\text { of } \mathrm{Cl}^{-} \text {in } \\
\text { ACPRef } \\
\left(\% \mathrm{Cl}^{-}\right)\end{array}$ & $\begin{array}{c}\text { BCPRef } \\
\left(\% \mathrm{Cl}^{-}\right)\end{array}$ & $\begin{array}{c}\text { Increase } \\
\text { of } \mathrm{Cl}^{-} \text {in } \\
\text { BCPRef } \\
\left(\% \mathrm{Cl}^{-}\right)\end{array}$ \\
\hline $0-2$ & 0.29 & & & & & & & & \\
\hline $2-4$ & 1.96 & 10.32 & 8.37 & 6.69 & 4.74 & 12.26 & 10.30 & 8.69 & 6.73 \\
\hline $4-6$ & 1.93 & 5.37 & 3.44 & 5.66 & 3.72 & 10.96 & 9.03 & 7.97 & 6.03 \\
\hline $6-8$ & 1.82 & 5.97 & 4.16 & 6.25 & 4.43 & 10.51 & 8.69 & 6.85 & 5.03 \\
\hline $8-10$ & 1.77 & 6.01 & 4.24 & 6.43 & 4.66 & 10.36 & 8.59 & 7.06 & 5.29 \\
\hline $10-12$ & 1.90 & 5.11 & 3.21 & 6.26 & 4.36 & 8.97 & 7.07 & 5.01 & 3.11 \\
\hline $12-14$ & 2.01 & 5.10 & 3.09 & 5.51 & 3.50 & 8.70 & 6.69 & 5.00 & 2.99 \\
\hline $14-16$ & 1.95 & 4.62 & 2.67 & 4.72 & 2.77 & 9.75 & 7.80 & 4.83 & 2.87 \\
\hline $16-18$ & 2.13 & 3.88 & 1.74 & 3.88 & 1.74 & 6.64 & 4.51 & 4.99 & 2.85 \\
\hline $18-20$ & 2.30 & 3.92 & 1.63 & 3.07 & 0.77 & 5.12 & 2.82 & 4.34 & 2.05 \\
\hline Average & 1.97 & 5.59 & 3.61 & 5.38 & 3.41 & 9.25 & 7.28 & 6.08 & 4.11 \\
\hline
\end{tabular}

Table 3. Local $\mathrm{Cl}^{-}$contents (expressed in $\% \mathrm{Cl}^{-}$relative to cement mass) before and after the $1^{\text {st }}$ phase of 24 weeks, with $\mathrm{CP}$ and $\mathrm{Cl}^{-}$contamination, and the differences (penetration of $\mathrm{Cl}^{-}$). Comparison between results for both routes of contamination, with $\mathrm{CP}(\mathrm{ACP}-\mathrm{BCP})$ and reference samples without CP (ACPRef - BCPRef). Adapted from [20].

In Table 3, averages represent the arithmetic mean of $\mathrm{Cl}^{-}$content measured through the whole profile. 10 dust samples were always analyzed of every core sample, and every dust sample was extracted from $2 \mathrm{~mm}$ thickness of each core sample.

In the light of these results, it can be concluded that for a concrete without protection treatment, the $\mathrm{Cl}^{-}$contamination produced by A (immersion $\mathrm{NaCl} 1 \mathrm{M}$ ) is much more aggressive than that produced by $\mathrm{B}(65 \mathrm{cc}$ of $\mathrm{NaCl} 0.5 \mathrm{M}$ weekly sprayed). As is shown in Table 3, $\mathrm{Cl}^{-}$average increase was $7.28 \%$ for ACPRef against $4.11 \%$ for BCPRef, $77.13 \%$ higher for A. However, when $\mathrm{CP}$ is applied, both trends are almost equal. $\mathrm{Cl}^{-}$average increase was in this case $3.61 \%$ for ACP, and $3.41 \%$ for BCP, only $5.87 \%$ higher for ACP.

The "barrier effect" of CP was stated in previous researches [21]. In this work it is defined as the difference in percentage between the average of the increase of $\mathrm{Cl}^{-}$of a sample 
subjected to $\mathrm{CP}$ and the increase of $\mathrm{Cl}^{-}$of the reference sample, without electrochemical treatment, both subjected to the same kind of contamination. Percentages above referred are relative to penetration in reference samples without electrochemical treatment.

On the other hand, the "barrier effect" becomes greater for A contamination $(7.279 \%$ $3.615 \%=3.664 \%, 50.34 \%$ less $\mathrm{Cl}^{-}$increase with $\left.\mathrm{CP}\right)$ than for $\mathrm{B}$ contamination $(4.107 \%$ $3.410 \%=0.697 \%, 16.97 \%$ less $\mathrm{Cl}^{-}$increase with $\mathrm{CP}$ ). It seems that this "barrier effect" is directly related to the level of contamination.

\subsection{CPre treatment $1^{\text {st }}$ phase}

To start with, it should be recalled that CPre was applied to "non-saline series" of samples. Results obtained with the application of CPre (impressed current density $2 \mathrm{~mA} / \mathrm{m}^{2}$ ) are described below. $\boldsymbol{E}_{\text {corr }}$ data did not follow the trend obtained with CP. In just 5 weeks, A contamination behaved more aggressively than B. Fig. 11 shows the evolution of $\boldsymbol{E}_{\text {corr }}$ values for CPre and both types of contamination.

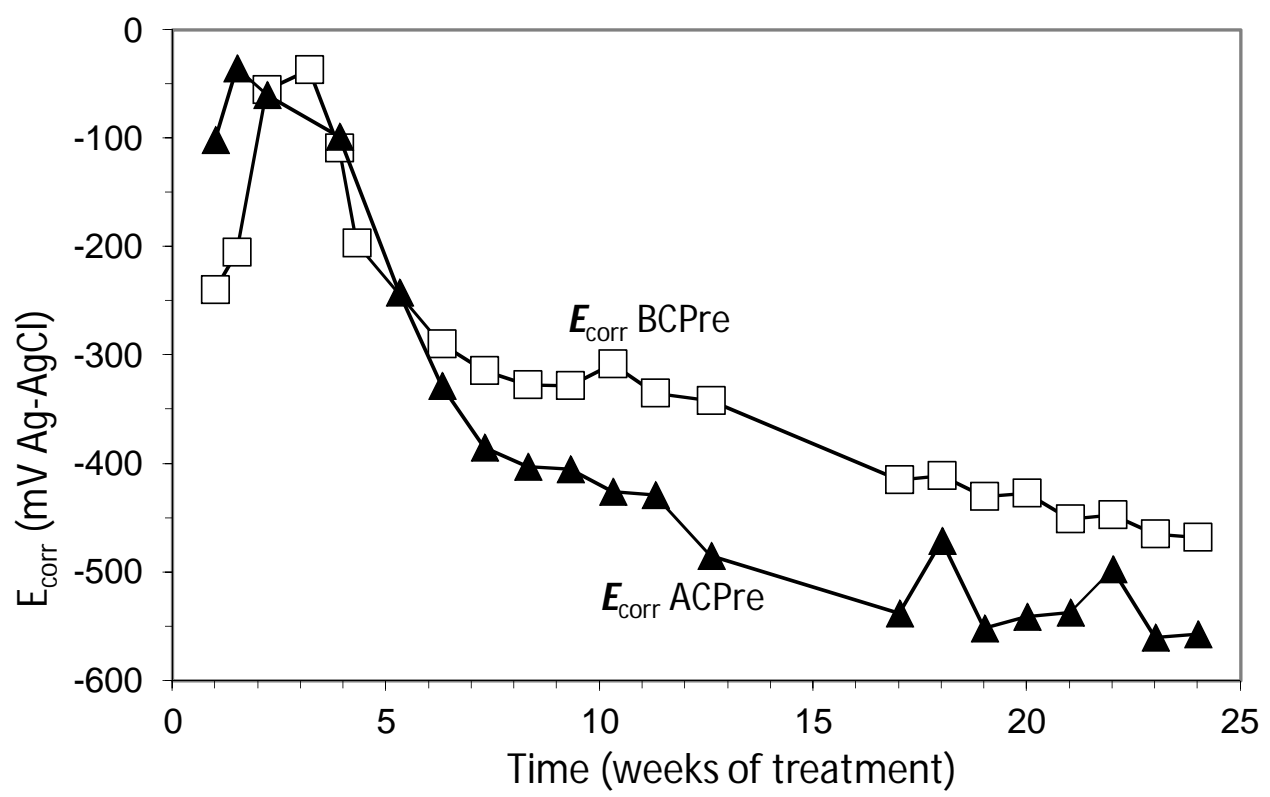

Figure 11. Evolution of $\boldsymbol{E}_{\text {corr }}$ for ACPre and BCPre along CPre treatment ( $1^{\text {st }}$ phase of 24 weeks). ACPre is the A contaminated sample, BCPre is the B contaminated sample. Current density: $2 \mathrm{~mA} / \mathrm{m}^{2}$, relative to exposed concrete surface. Current switched off between weeks 13 to 17. Adapted from [20]. 


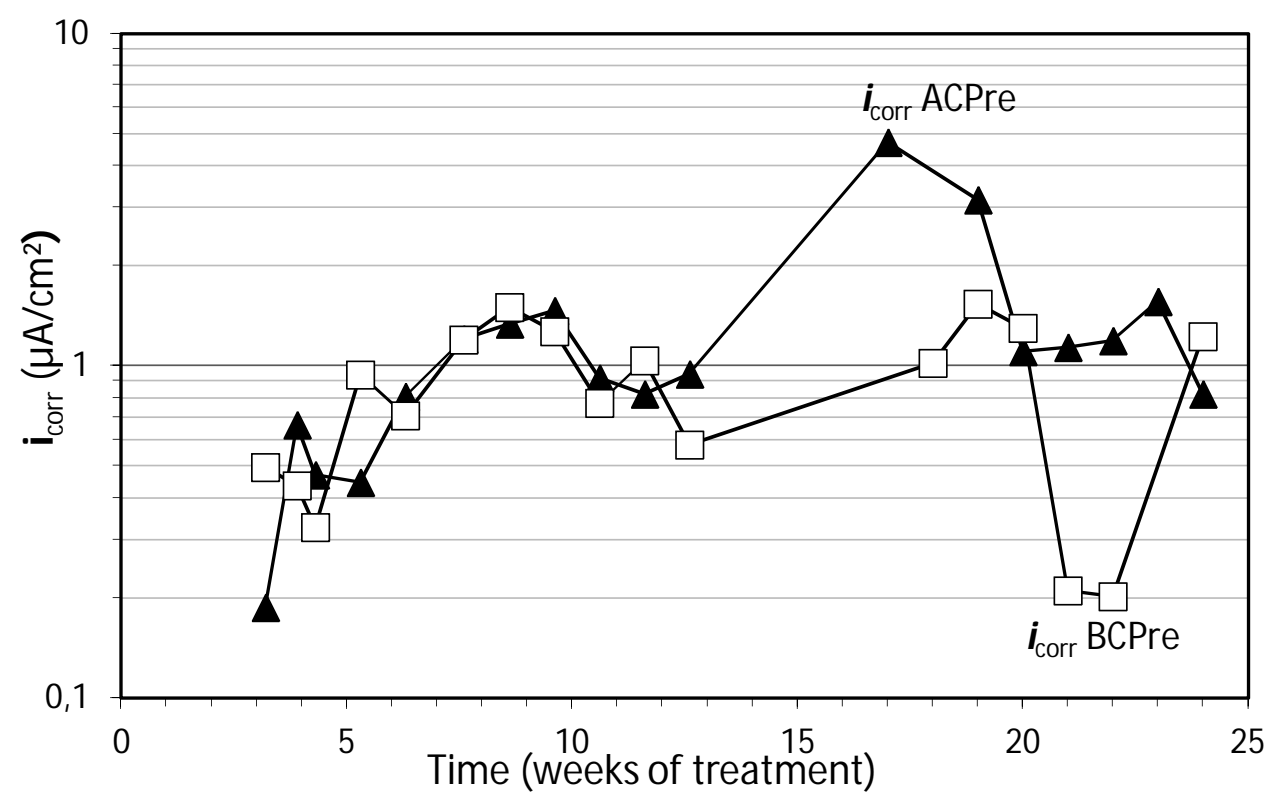

Figure 12. Evolution of $\boldsymbol{i}_{\text {corr }}$ for ACPre and BCPre along CPre treatment $\left(1^{\text {st }}\right.$ phase of 24 weeks). ACPre is the A contaminated sample, BCPre is the B contaminated sample. Current density: $2 \mathrm{~mA} / \mathrm{m}^{2}$, relative to exposed concrete surface. Current switched off between weeks 13 to 17. Adapted from [20].

Corrosion rate $\boldsymbol{i}_{\text {corr }}$ showed very similar values until the stop of treatment. After the reconnection, these values were higher for A. See Figure 12.

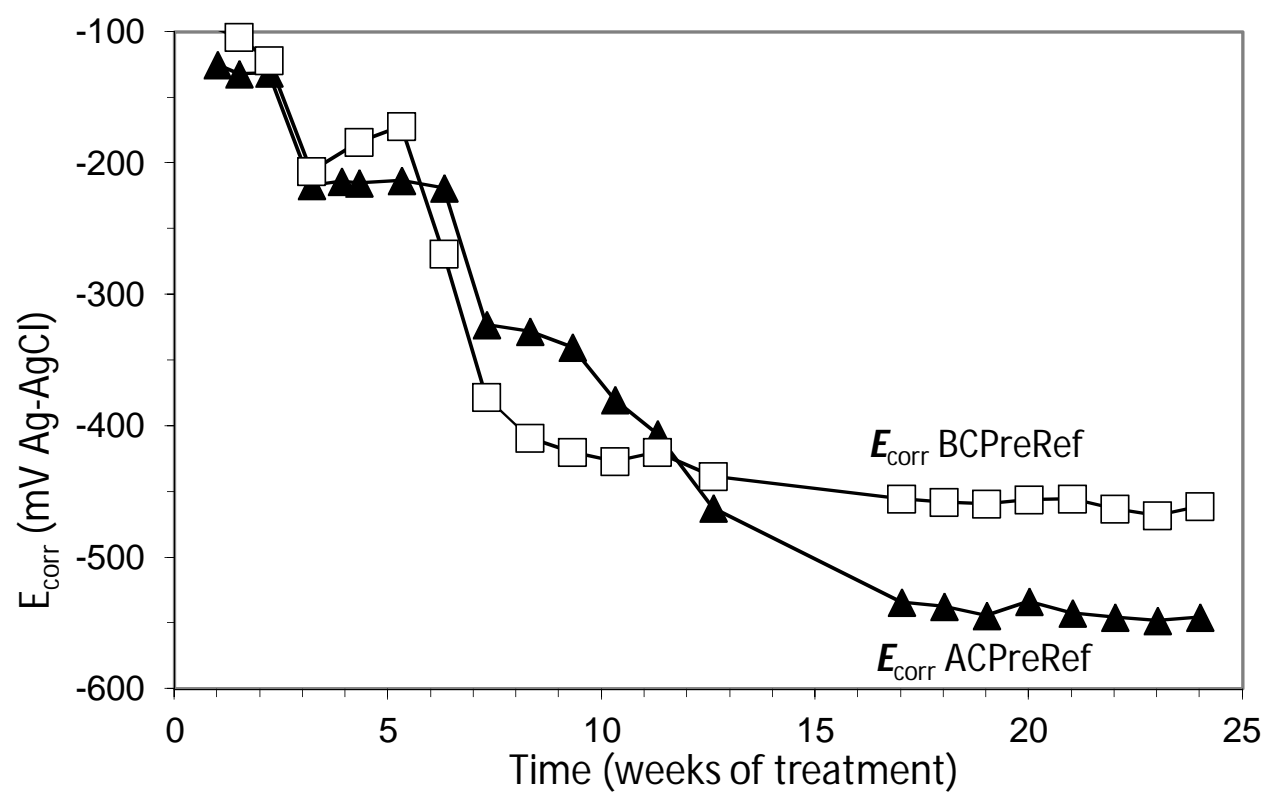

Figure 13. Evolution of $\boldsymbol{E}_{\text {corr }}$ for ACPreRef and BCPreRef along the $1^{\text {st }}$ phase of the testing program (24 weeks). ACPreRef is the A contaminated sample, BCPreRef is the B contaminated sample. Adapted from [20]. 
Regarding the reference samples, $\boldsymbol{E}_{\text {corr }}$ values were similar. After week 13, A showed clearly more negative $\boldsymbol{E}_{\text {corr }}$ values than B. See Figure 13.

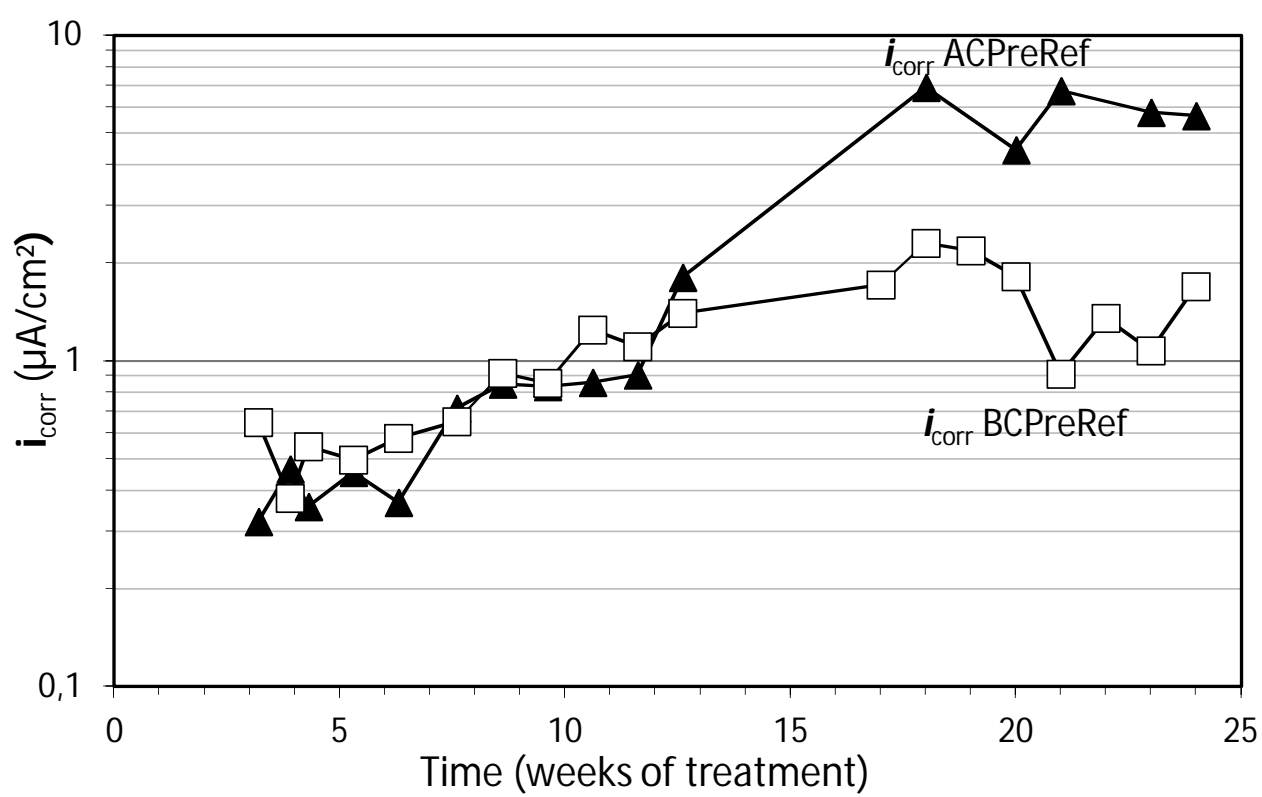

Figure 14. Evolution of $\boldsymbol{i}_{\text {corr }}$ for ACPreRef and BCPreRef along the $1^{\text {st }}$ phase of the testing program (24 weeks). ACPreRef is the A contaminated sample, BCPreRef is the B contaminated sample. Adapted from [20].

Corrosion rate $\left(\boldsymbol{i}_{\text {corr }}\right)$ values were also very similar. After week 13 , A caused higher values than B. See Figure 14.

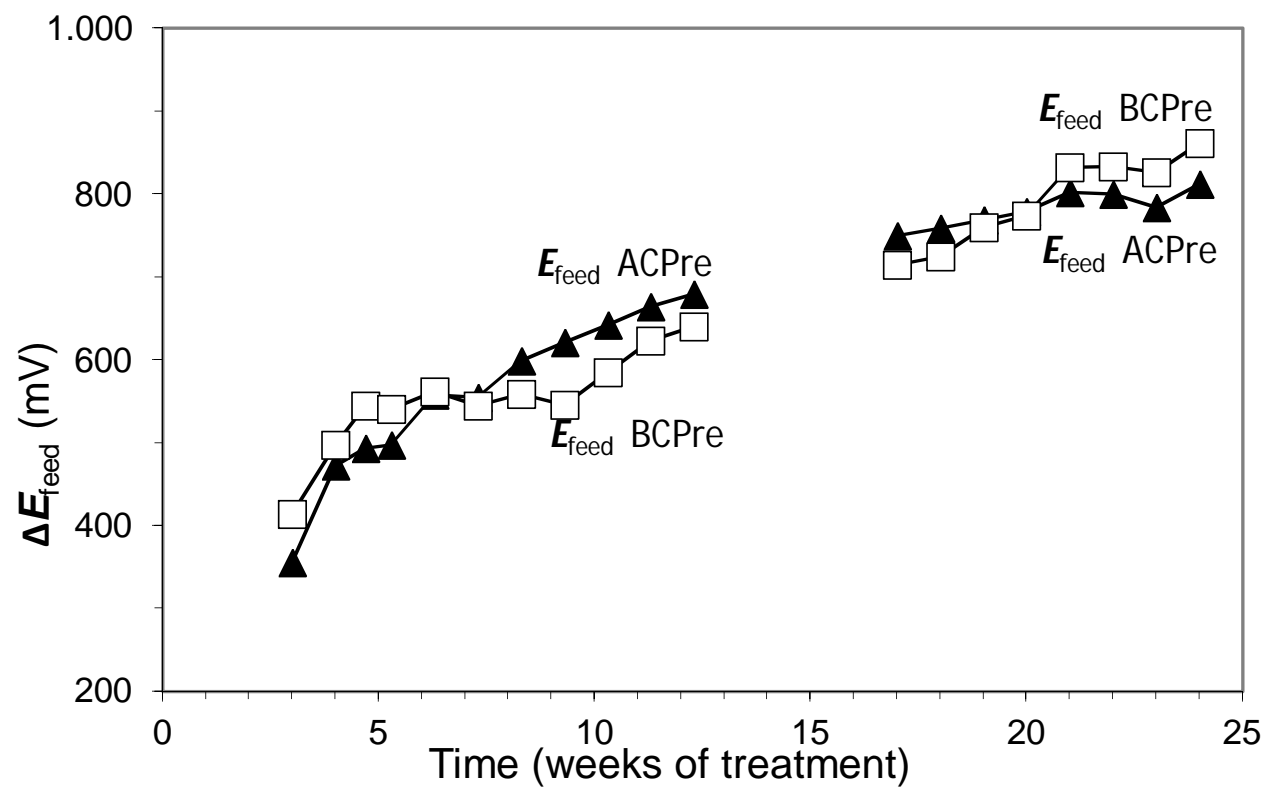

Figure 15. Evolution of $\Delta \boldsymbol{E}_{\text {feed }}$ for ACPre and BCPre along CPre treatment ( $1^{\text {st }}$ phase of 24 weeks). ACPre is the A contaminated sample, BCPre is the B contaminated sample. 
Current density: $2 \mathrm{~mA} / \mathrm{m}^{2}$, relative to exposed concrete surface. Current switched off between weeks 13 to 17. Adapted from [20].

When $\Delta \boldsymbol{E}_{\text {feed }}$ was compared, the notable difference shown in CP did not appear in CPre. Indeed, in this case both routes of contamination gave similar values. See Figure 15.

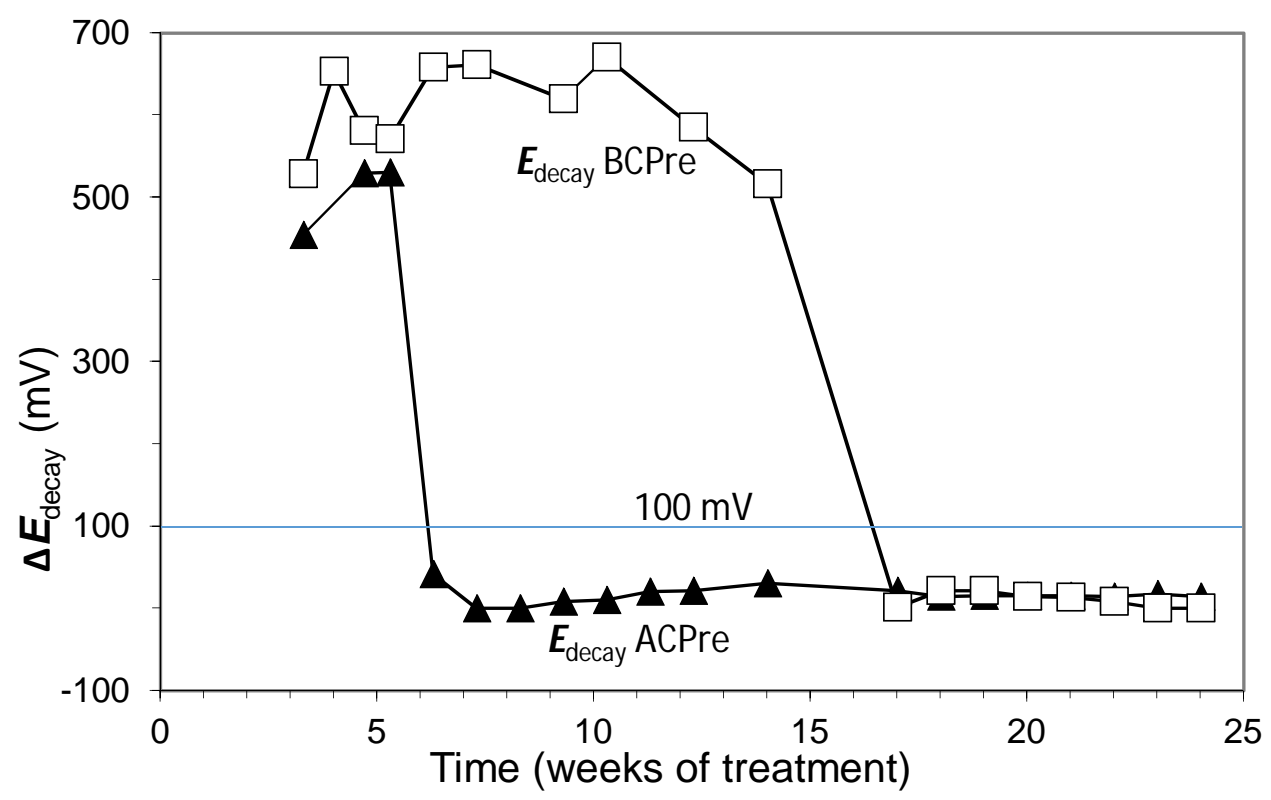

Figure 16. Evolution of $\Delta \boldsymbol{E}_{\text {decay }}$ for ACPre and BCPre along CPre treatment ( $1^{\text {st }}$ phase of 24 weeks). ACPre is the A contaminated sample, BCPre is the B contaminated sample. Current density: $2 \mathrm{~mA} / \mathrm{m}^{2}$, relative to exposed concrete surface. Current switched off between weeks 13 to 17. Adapted from [20].

Data collected in Figure 16 were very illustrative about the compared contaminant competencies between both routes of contamination in CPre. With A, CPre was only able to keep protection conditions during 5 weeks. In contrast, when contamination way was B, only the stop of the treatment (week 13) caused the loss of steel passivation. See Figure 16. 


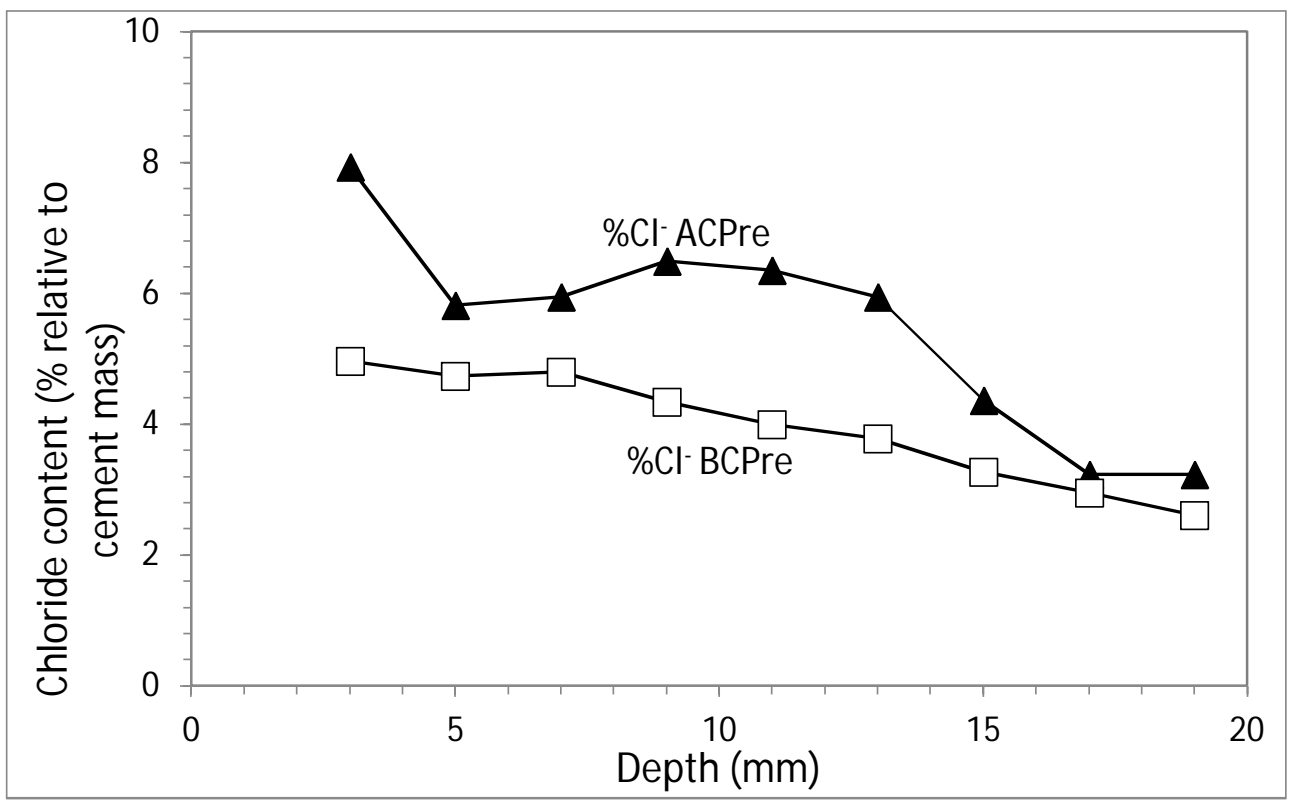

Figure 17. Profiles of $\mathrm{Cl}^{-}$content in samples subjected to CPre, ACPre and BCPre at the end of the $1^{\text {st }}$ phase of 24 weeks. Adapted from [20].

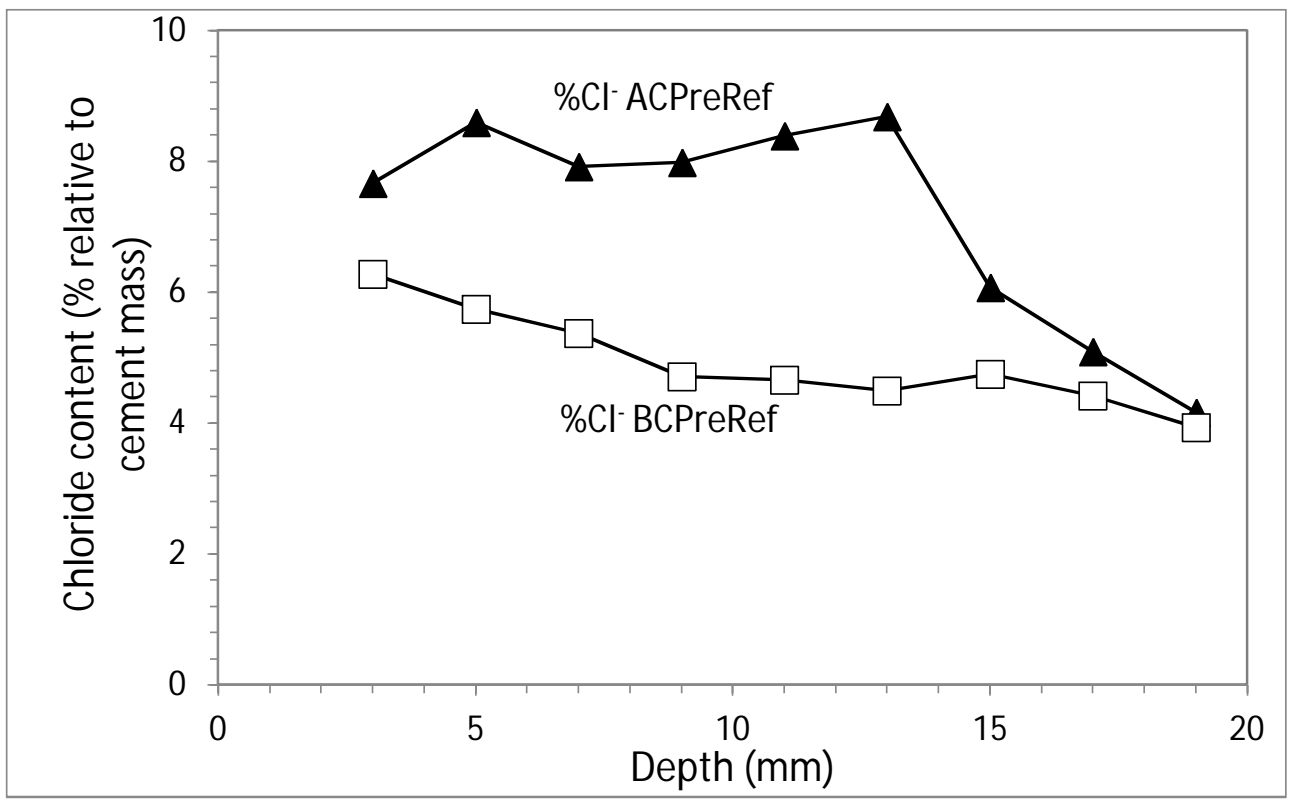

Figure 18. Profiles of $\mathrm{Cl}^{-}$content in reference samples for CPre, ACPreRef and BCPreRef at the end of the $1^{\text {st }}$ phase of 24 weeks.

Regarding the comparison of $\mathrm{Cl}^{-}$profiles, A provoked more contamination than $\mathrm{B}$ with CPre. See Figures 17 and 18. Proof is also in data collected in Table 4. Here, a Cl- increase of $5.26 \%$ for ACPre versus $3.72 \%$ for BCPre is shown, $41.40 \%$ higher for A. Also, $6.96 \%$ for ACPreRef versus $4.71 \%$ for BCPreRef, $47.8 \%$ higher for A. A clearly behaved more contaminant than B. 


\begin{tabular}{|c|c|c|c|c|c|c|c|c|c|}
\hline $\begin{array}{l}\text { Depth } \\
(\mathbf{m m})\end{array}$ & $\begin{array}{c}\text { Initial } \mathrm{Cl}^{-} \\
\text {contents } \\
\text { of "non } \\
\text { saline } \\
\text { series" } \\
\text { samples } \\
\left(\% \mathrm{Cl}^{-}\right)\end{array}$ & $\begin{array}{l}\text { ACPre } \\
\left(\% \mathrm{Cl}^{-}\right)\end{array}$ & $\begin{array}{c}\text { Increase } \\
\text { of } \mathrm{Cl}^{-} \text {in } \\
\mathrm{ACPre}^{-} \\
\left(\% \mathrm{Cl}^{-}\right)\end{array}$ & $\begin{array}{l}\text { BCPre } \\
\left(\% \mathrm{Cl}^{-}\right)\end{array}$ & $\begin{array}{l}\text { Increase } \\
\text { of } \mathrm{Cl}^{-} \text {in } \\
\mathrm{BCPre}^{-} \\
\left(\% \mathrm{Cl}^{-}\right)\end{array}$ & $\begin{array}{c}\text { ACPre } \\
\text { Ref } \\
\left(\% \mathrm{Cl}^{-}\right)\end{array}$ & $\begin{array}{c}\text { Increase } \\
\text { of } \mathrm{Cl}^{-} \text {in } \\
\text { ACPre } \\
\text { Ref } \\
\left(\% \mathrm{Cl}^{-}\right)\end{array}$ & $\begin{array}{l}\text { BCPreR } \\
\text { ef }\left(\% \mathrm{Cl}^{-}\right)\end{array}$ & $\begin{array}{c}\text { Increase } \\
\text { of } \mathrm{Cl}^{-} \text {in } \\
\text { BCPre } \\
\text { Ref } \\
\left(\% \mathrm{Cl}^{-}\right)\end{array}$ \\
\hline \multicolumn{10}{|l|}{$0-2$} \\
\hline $2-4$ & 0.19 & 7.93 & 7.74 & 4.96 & 4.77 & 7.66 & 7.47 & 6.27 & 6.08 \\
\hline $4-6$ & 0.23 & 5.82 & 5.59 & 4.73 & 4.50 & 8.59 & 8.36 & 5.75 & 5.52 \\
\hline $6-8$ & 0.24 & 5.95 & 5.71 & 4.80 & 4.56 & 7.91 & 7.67 & 5.37 & 5.13 \\
\hline $8-10$ & 0.23 & 6.49 & 6.26 & 4.34 & 4.12 & 7.99 & 7.76 & 4.72 & 4.49 \\
\hline $10-12$ & 0.21 & 6.35 & 6.14 & 4.00 & 3.79 & 8.39 & 8.18 & 4.66 & 4.44 \\
\hline $12-14$ & 0.20 & 5.94 & 5.74 & 3.786 & 3.58 & 8.68 & 8.47 & 4.49 & 4.29 \\
\hline $14-16$ & 0.20 & 4.37 & 4.17 & 3.27 & 3.07 & 6.08 & 5.88 & 4.75 & 4.55 \\
\hline $16-18$ & 0.22 & 3.23 & 3.01 & 2.95 & 2.73 & 5.10 & 4.88 & 4.42 & 4.20 \\
\hline $18-20$ & 0.23 & 3.23 & 3.01 & 2.61 & 2.39 & 4.16 & 3.94 & 3.93 & 3.71 \\
\hline Average & 0.22 & 5.48 & 5.26 & 3.94 & 3.72 & 7.17 & 6.96 & 4.93 & 4.71 \\
\hline
\end{tabular}

Table 4. Local $\mathrm{Cl}^{-}$contents (expressed in $\% \mathrm{Cl}^{-}$relative to cement mass) before and after the $1^{\text {st }}$ phase of 24 weeks, with $\mathrm{CPre}$ and $\mathrm{Cl}^{-}$contamination, and the differences (penetration of $\mathrm{Cl}^{-}$). Comparison between results for both routes of contamination, with CPre (ACPre BCPre) and reference samples without CPre (ACPreRef - BCPreRef). Adapted from [20].

Although at lower rates than in the case of CP, when CPre was applied the "barrier effect" kept directly related to the level of contamination. Indeed, for A contamination the barrier effect was $6.957-5.263=1.694,24.35 \%$, while for B, $4.712-3.724=0.988,20.97 \%$ was obtained. Those percentages are relative to penetration in reference samples without electrochemical treatment). See Table 4.

All collected data noted that CPre is a reliable method to prevent corrosion in reinforced concrete structures when it is expected a $\mathrm{Cl}^{-}$contamination of the type represented by $\mathrm{B}$ : wetdry cycles of occasional $\mathrm{Cl}^{-}$contamination, as in the case of de-icing salt applications on road structures. However, when a more aggressive kind of contamination is expected (as type A), CPre is not advisable.

3.3. CP treatment $2^{\text {nd }}$ phase. Recovery of protection conditions. 
Once the above referred $1^{\text {st }}$ phase of 24 weeks was concluded, laboratory samples presented $\mathrm{Cl}^{-}$levels as high as the ones included in Tables 3 and 4. In all cases, the steel reinforcement had lost their protection conditions. In order to find out the ability of CP to retrieve the steel passivity in structural element with such a high content of $\mathrm{Cl}^{-}$, a $2^{\text {nd }}$ phase was started. CP was applied to samples previously subjected to both electrochemical treatments, with higher current densities, and now without any kind of $\mathrm{Cl}^{-}$contamination.

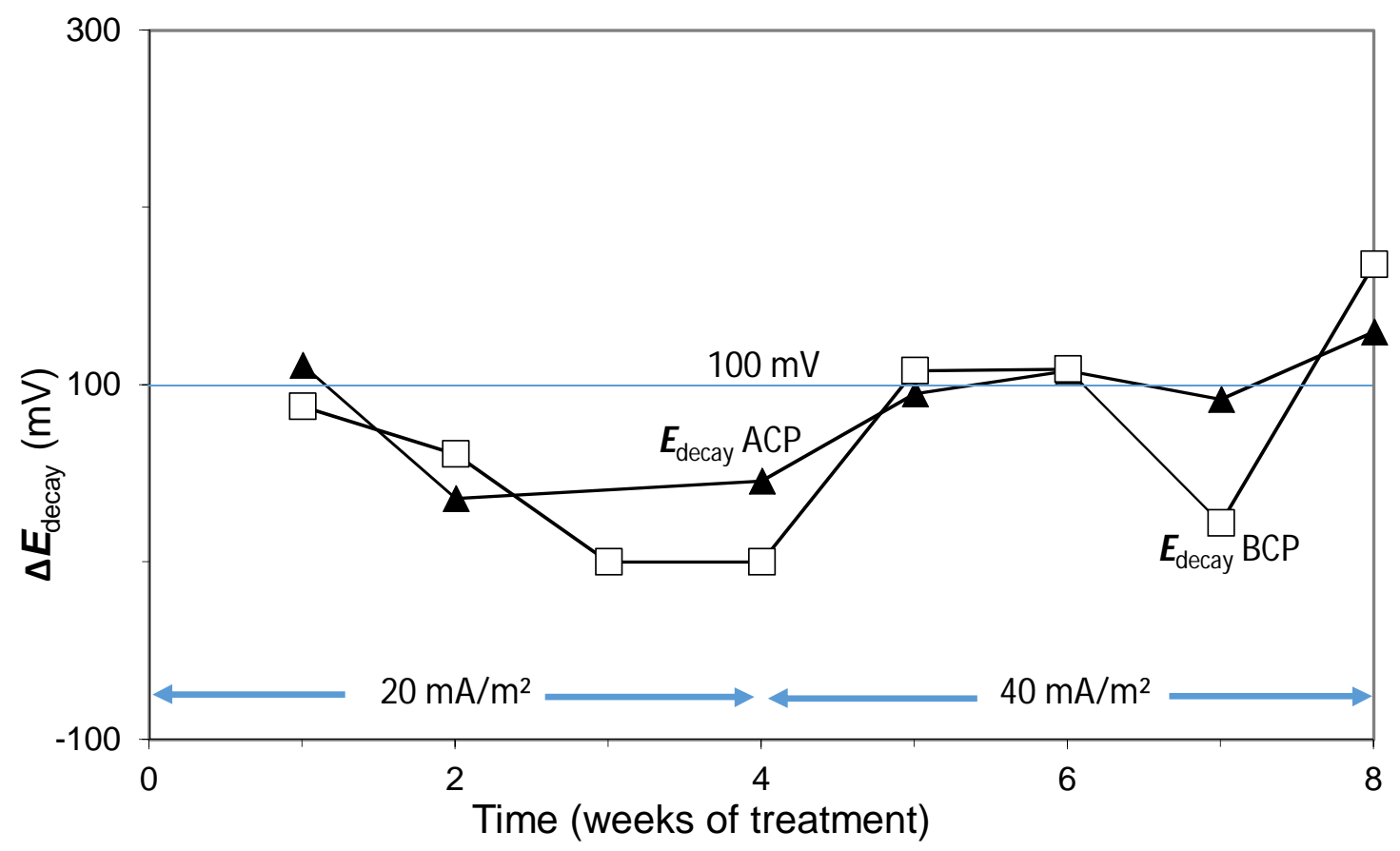

Figure 19. Evolution of $\Delta \boldsymbol{E}_{\text {decay }}$ during $2^{\text {nd }}$ phase of CP. First step of 4 weeks with 20 $\mathrm{mA} / \mathrm{m}^{2}$ of current density and final step with $40 \mathrm{~mA} / \mathrm{m}^{2}$ are only represented, for specimens ACP and BCP. Adapted from [20]. 


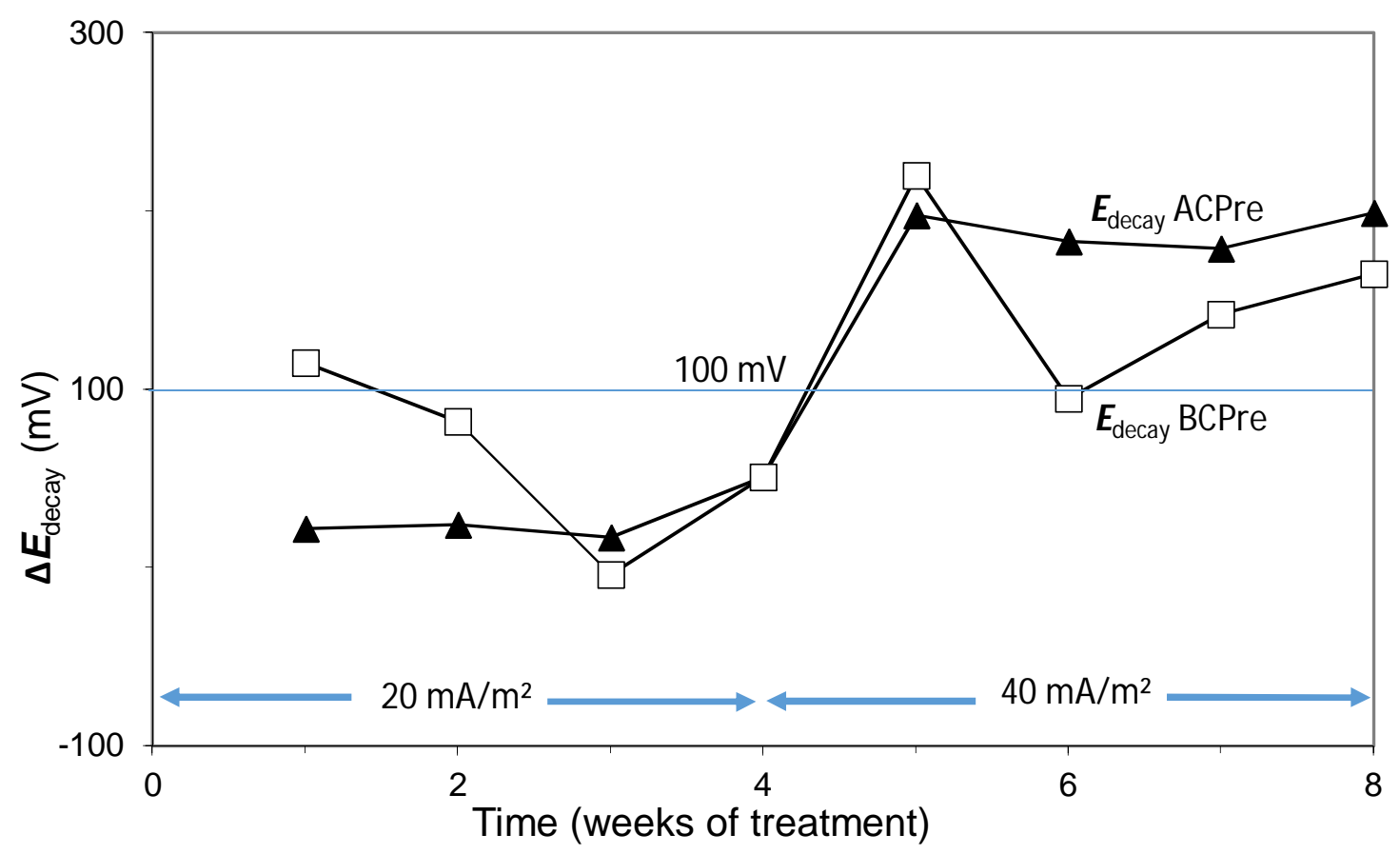

Figure 20. Evolution of $\Delta \boldsymbol{E}_{\text {decay }}$ during $2^{\text {nd }}$ phase of CP. First step of 4 weeks with 20 $\mathrm{mA} / \mathrm{m}^{2}$ of current density and final step with $40 \mathrm{~mA} / \mathrm{m}^{2}$ are only represented, for specimens ACPre and BCPre. Adapted from [20].

To start this new phase, $\mathrm{CP}$ was applied with $20 \mathrm{~mA} / \mathrm{m}^{2}$. At the end of 4 weeks, passivity conditions were not reached. Consequently, current density was increased again in steps of 5 $\mathrm{mA} / \mathrm{m}^{2}$ of current density increase, each one during 4 weeks. The expected outcome was not achieved until the step of $40 \mathrm{~mA} / \mathrm{m}^{2}$. At this level and 4 weeks of CP application, $\Delta \boldsymbol{E}_{\text {decay }}$ values confirmed the return to steel protection conditions on every one of the treated samples. See Figures 19 and 20.

To confirm this conclusion, protection conditions were verified with depolarization potential difference values 7 days after switch off [28]. Values above $150 \mathrm{mV}$ were obtained after 7 days, for samples subjected to both types of treatment and both routes of contamination. See Table 5. 


\begin{tabular}{ccccc}
\hline \multirow{2}{*}{$\begin{array}{c}\text { Routes of } \\
\text { contamination }\end{array}$} & Samples & $\begin{array}{c}\mathrm{Cl}^{-} \text {content } \\
\text { average }(\% \\
\text { relative to } \\
\text { cement mass })\end{array}$ & $\begin{array}{c}\mathrm{Cl}^{-} \text {content in } \\
\text { rebar vicinity } \\
(\% \text { relative to } \\
\text { cement mass })\end{array}$ & $\begin{array}{c}\text { Depolarization at 7 } \\
\text { days (mV) }\end{array}$ \\
\hline A & ACP & 5.59 & 3.92 & 217 \\
contamination & ACPre & 5.48 & 3.23 & 211 \\
\hline B contamination & BCP & 5.38 & 3.07 & 487 \\
\hline
\end{tabular}

Table 5. Measurements of depolarization of each one of the electrochemically treated samples 7 days after the switch off.

Results were unquestionable. Even in highly $\mathrm{Cl}^{-}$contaminated elements, $\mathrm{CP}$ had proved effective to restore the lost protection conditions of reinforced concrete steel. CP and CPre have the effect of reducing the $\mathrm{Cl}^{-}$content to a greater extent in the vicinity of steel. Therefore, in this regard it should be also considered the final $\mathrm{Cl}^{-}$content just in rebar contact. See Table 5. Even so, $\mathrm{Cl}^{-}$contents close to rebar in the range $2.5-4 \% \mathrm{Cl}^{-}$(relative to cement mass in concrete) did not impede the restoration of the passivation conditions of steel reinforcement. This result is in agreement with previous works in this matter [31-33].

\section{Conclusions}

In the light of the results of this research, conclusions can be summarized as follow:

1. "A contamination" behaves significantly more aggressive than "B contamination". It is confirmed by checking the reference samples (ACPRef, BCPRef, ACPreRef and ACPreRef). However, when CP was applied, both types of contamination resulted in similar effects regarding the corrosion state, the barrier effect (the stronger level of $\mathrm{Cl}^{-}$contamination, the higher the barrier effect) and the level of protection afforded. Therefore, when it comes to project a $\mathrm{CP}$ treatment in order to protect a reinforced concrete structure, the route of $\mathrm{Cl}^{-}$contamination is not determinant. The choice of the appropriated current density is only dependent on the initial $\mathrm{Cl}^{-}$content of the concrete to be protected.

2. CP has shown its capability to keep and return to steel protection conditions even for a high level of $\mathrm{Cl}^{-}$content in the reinforced concrete. The question is to select the right impressed current density in each case, according to the reached $\mathrm{Cl}^{-}$content.

3. The GC anode has proved its good performance to apply CP and CPre without significant damages in the experimental conditions tested in this work. 
4. In the case of CPre, the samples subjected to "B contamination" showed a sufficient level of protection, keeping the steel rebar in protection conditions. However, CPre was unable to maintain this protection for "A contamination". Therefore, CPre is not advisable if the reinforced concrete element will be subjected to a high level of contamination.

\section{Acknowledgments}

This research was funded by the Spanish Ministerio de Economía y Competitividad (and formerly by the Spanish Ministerio de Ciencia e Innovación) and ERDF (European Regional Development Fund) through projects BIA2010-20548 and MAT2009-10866, and also through the project PROMETEO/2013/035 of Generalitat Valenciana (Spain).

Authors would like to dedicate this work to the memory of our friend and maestro Professor Antonio Aldaz.

\section{REFERENCES}

[1]. J.A. Jeong, C.K. Jin. "Experimental studies of effectiveness of hybrid cathodic protection system on the steel in concrete". Science and Advanced Materials. 6 (10) (2014) 2165-2170.

[2]. A. Aldaz, Electroquímica (Electrochemistry) Vol. 3, Ed. Universidad Nacional de Educación a Distancia, Madrid, Spain (1976). (In Spanish).

[3]. G.K. Glass, J.R. Chadwick. "An investigation into the mechanisms of protection afforded by a cathodic current and the implications for advances in the field of cathodic protection". Corrosion Science. 36 (1994) 2193-2209.

[4]. R.F. Stratful. "Cathodic protection of a bridge deck - preliminary investigation". Materials Performance. 13 (4) (1974) 24-25.

[5]. P. Pedeferri, L. Bertolini. "La durabilità del calcestruzzo armato", McGraw-Hill, Milano. ISBN 88386 0845-8. 2000.

[6]. L. Bertolini, B. Elsener, P. Pedeferri, R. Polder "Corrosion of Steel in Concrete", WileyVch. ISBN 978-3-527-30800-2. 2004.

[7]. P.M. Chess, J. Broomfield. "Cathodic protection of steel in concrete and masonry, $2^{\text {nd }}$ edition”, CRC Press-Taylor\&Francis Group. ISBN 978-0-203-93807-2; 978-0-415-395038.

[8]. D.D.L. Chung. "Electrically conductive cement-based materials". Advances in Cement Research. 16 (4) (2004) 167-176. 
[9]. X. Fu, D.D.L. Chung. "Carbon fiber reinforced mortar as an electrical contact material for cathodic protection". Cement and Concrete Research. 25 (4) (1995) 689-694.

[10]. J. Hou, D.D.L. Chung, Cathodic protection of steel reinforced concrete facilitated by using carbon fiber reinforced mortar or concrete, Cement and Concrete Research. 27 (5) (1997) 649-656.

[11]. L. Bertolini, F. Bolzoni, T. Pastore, P. Pedeferri. "Effectiveness of a conductive cementitious mortar anode for cathodic protection of steel in concrete". Cement and Concrete Research. 34 (4) (2004) 681-694.

[12]. J. Xu, W. Yao. "Electrochemical studies on the performance of conductive material in cathodic protection of reinforced concrete". Construction and Building Materials. 25 (2011) 2655-2662.

[13]. G. Qiao, B. Guo, Y. Hong, J. Ou. "Multi-scale carbon-admixtures enhanced cementitious anodic materials for the impressed current cathodic protection of RC structures". International Journal of Electrochemical Science. 10 (2015) 8423-8436.

[14]. M. Funahashi, T. Sirola, D. McInaggart. "Cost effective cathodic protection system for concrete structures". Materials Performance. 53 (11) (2014) 32-37.

[15]. M.S. Anwar, B. Sujitha, R. Vedalakshmi. "Light-weight cementitious anode for impressed current cathodic protection of steel reinforced concrete application". Construction and Building Materials. 71 (2014) 167-180.

[16]. E. Redaelly, L. Bertolini. "Macroscopic observations on the long-term effects of cathodic protection applied to carbonated reinforced concrete”. Materials and Corrosion. 66 (8) (2015) 756-762.

[17]. A. Pérez, M.A. Climent, P. Garcés. "Electrochemical extraction of chlorides from reinforced concrete using a conductive cement paste as the anode". Corrosion Science. 52 (2010) 1576-1581.

[18]. A. Cañón, P. Garcés, M.A. Climent, J. Carmona, E. Zornoza. "Feasibility of electrochemical chloride extraction from structural reinforced concrete using a sprayed conductive graphite powder-cement as anode", Corrosion Science. 77. (2013) 128-134.

[19]. J. Carmona, M. A. Climent, C. Antón, G. de Vera, P. Garcés. "Shape effect of electrochemical chloride extraction in structural reinforced concrete elements using a new cement-based anodic system”. Materials. 8 (2015) 2901-2917.

[20]. J. Carmona, P. Garcés, M.A. Climent. "Efficiency of a conductive cement-based anodic system for the application of cathodic protection, cathodic prevention and electrochemical chloride extraction to control corrosion in reinforced concrete structures". Corrosion Science. 96 (2015) 102-111.

[21]. P. Pedeferri. "Cathodic protection and cathodic prevention". Construction and Building Materials. 10 (5) (1996) 391-402. 
[22]. L. Bertolini, F. Bolzoni, P. Pedeferri, L. Lazzari, T. Pastore. "Cathodic protection and cathodic prevention in concrete principles and applications". Journal of Applied Electrochemistry. 28 (12) (1998) 1321-1331.

[23]. O. Galao, F.J. Baeza, E. Zornoza, P. Garcés. "Strain and damage sensing properties on multifunctional cement composites with CNF". Cement and Concrete Composites. 46 (2014) 90-98.

[24]. Ø. Vennesland, M.A. Climent, C. Andrade. "Recommendation of RILEM TC 178-TMC: testing and modeling chloride penetration in concrete. Methods for obtaining dust samples by means of grinding concrete in order to determine the chloride concentration profile". Materials and Structures. 46 (3) (2013) 337-344.

[25]. M.A. Climent, E. Viqueira, G. de Vera, M.M. López. "Analysis of acid-soluble chloride in cement, mortar and concrete by potentiometric titration without filtration steps". Cement and Concrete Research. 29 (6) (1999) 893-898.

[26]. M.A. Climent, G. de Vera, E. Viqueira, M.M. López. "Generalization of the possibility of eliminating the filtration step in the determination of acid-soluble chloride content in cement and concrete by potentiometric titration", Cement and Concrete Research. 34 (12) (2004) 2291-2295.

[27]. C. Andrade, C.Alonso, J. Gulikers, R. Polder, R. Cigna, Ø. Vennesland, M. Salta. "Test methods for on-site reinforcement corrosion rate measurement of steel reinforcement in concrete by means of the Polarization Resistance method. RILEM Recommendation of TC154. Electrochemical Techniques for measuring metallic corrosion". Materials and Structures. 37 (2004) 623-643.

[28]. European Committee of Standardization CEN. Technical Committee CEN/TC 219. ISO 12696: 2012(en). "Cathodic protection of steel in concrete".

[29]. L. Bertolini, F. Bolzoni, T. Pastore, P. Pedeferri. "Effectiveness of a conductive cementitious mortar anode for cathodic protection of steel in concrete". Cement and Concrete Research. 34 (4) (2004) 681-694.

[30]. G.K. Glass, A. M. Hassanein, N.R. Buenfeld. "Cathodic protection afforded by an intermittent current applied to reinforced concrete". Corrosion Science. 43 (2001) 11111131.

[31]. C. Christodoulou, G. Glass, J. Webb, S. Austin, C. Goodier. "Assessing the long term benefits of impressed current cathodic protection". Corrosion Science. 52 (2010) 2671-2679.

[32]. U. Angst, B. Elsener, C. K. Larsen, Ø. Vennesland. "Critical chloride content in reinforced concrete - A review". Cement and Concrete Research. 39 (2009) 1122-1138.

[33]. U. Angst, B. Elsener, C. Larsen, $\emptyset$. Vennesland. "Chloride induced reinforcement corrosion: Electrochemical monitoring of initiation stage and chloride threshold values". Corrosion Science. 53 (2011) 1451-1464. 